\title{
Statistical Analysis of Nitrate in Ground Water, West Salt River Valley, Arizona
}

By A.E. LONG, JAMES G. BROWN and D.J. GELLENBECK

U.S. GEOLOGICAL SURVEY

Water-Resources Investigations Report 97-4185 and

ARIZONA DEPARTMENT OF ENVIRONMENTAL QUALITY

Open-File Report 97-16

Prepared in cooperation with the

ARIZONA DEPARTMENT OF ENVIRONMENTAL QUALITY 


\section{U.S. DEPARTMENT OF THE INTERIOR \\ BRUCE BABBITT, Secretary}

U.S. GEOLOGICAL SURVEY

Mark Schaefer, Acting Director

The use of firm, trade, and brand names in this report is for identification purposes only and does not constitute endorsement by the U.S. Geological Survey.

For additional information write to:

District Chief

U.S. Geological Survey

Water Resources Division

520 N. Park Avenue, Suite 221

Tucson, AZ 85719-5035
Copies of this report can be purchased from:

U.S. Geological Survey

Information Services

Box 25286

Federal Center

Denver, CO 80225-0286 


\section{CONTENTS}

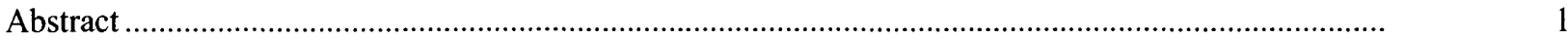

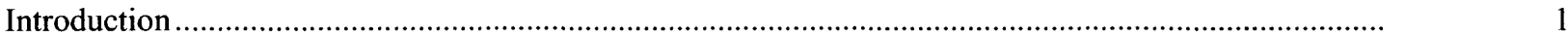

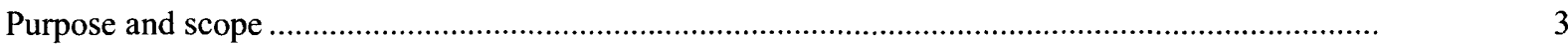

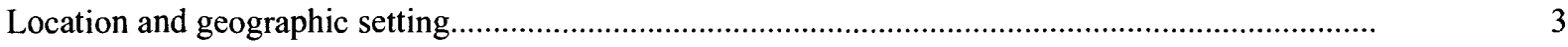

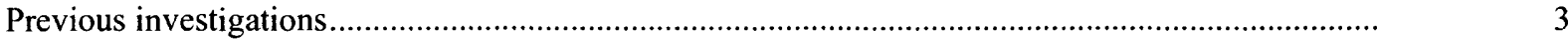

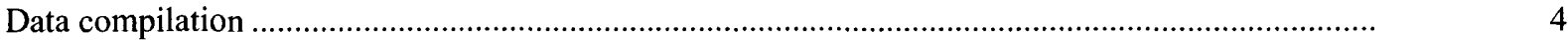

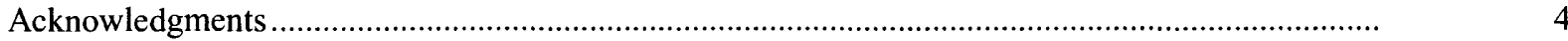

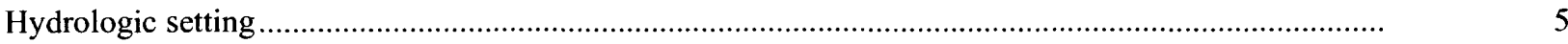

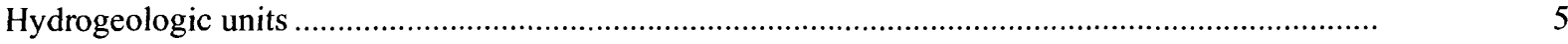

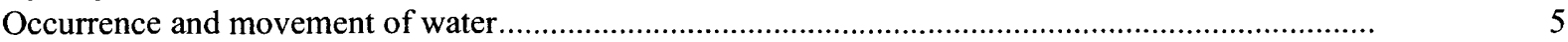

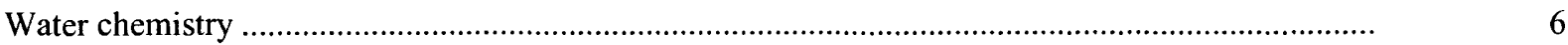

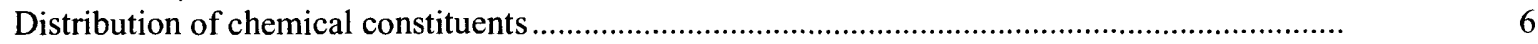

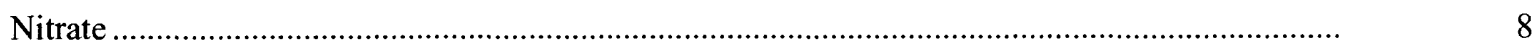

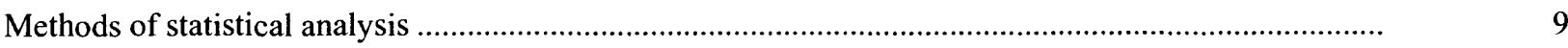

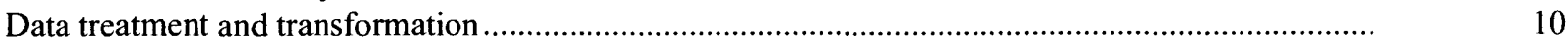

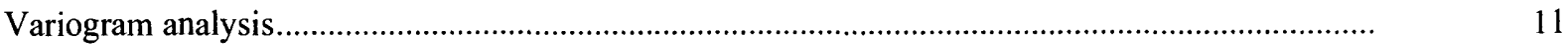

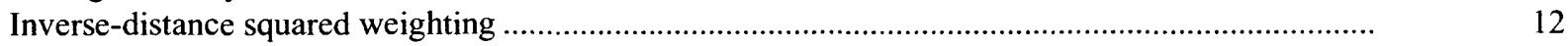

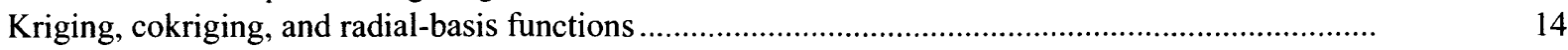

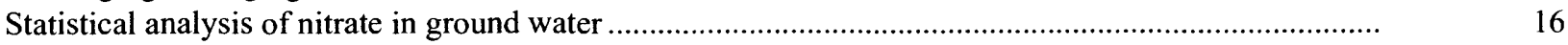

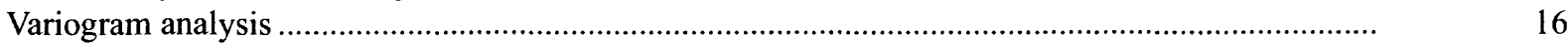

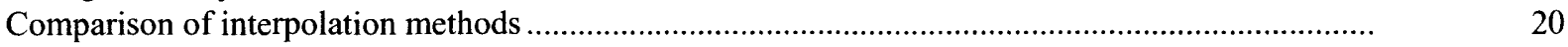

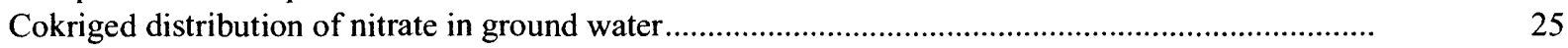

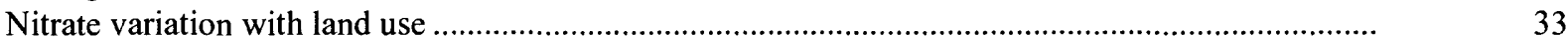

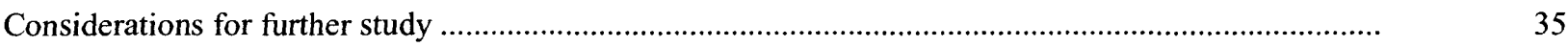

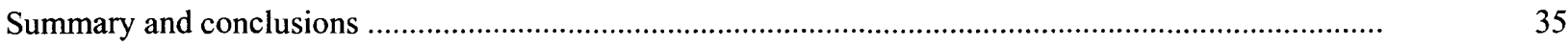

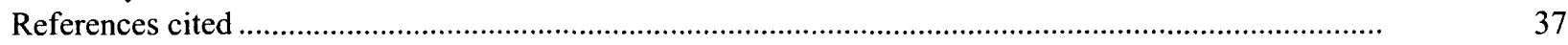

\section{FIGURES}

\section{1-2. Maps showing:}

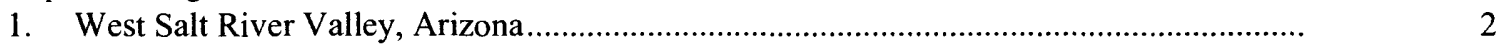

2. Altitude of the water table, west Salt River Valley, Arizona, 1992 ...................................

3. Trilinear diagram showing relative compositions of ground water, in percent, west

Salt River Valley, Arizona, 1986-91

4. Graph showing nitrate concentration at well (A-02-04)30acc, west Salt

River Valley, Arizona, 1934-88

5. Diagram showing statistical transformations and analyses used on water-chemistry

data, west Salt River Valley, Arizona.

6-9. Graphs showing:

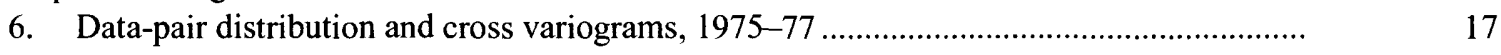

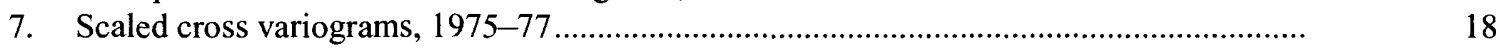

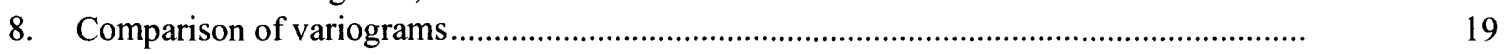

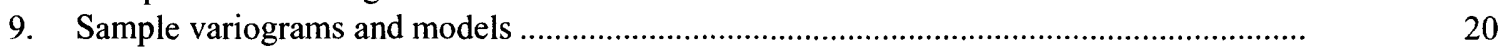

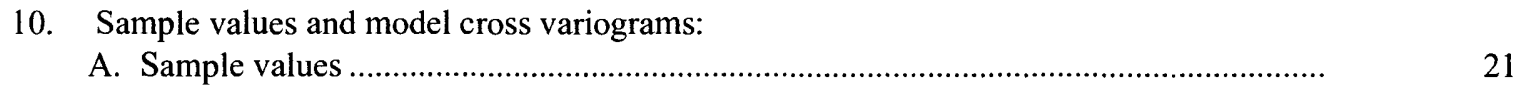

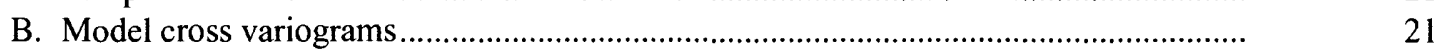


11. Plots showing contours of nitrate created by (A) radial-basis function, (B) inversedistance squared weighting, (C) cokriging, and (D) kriging

12-17. Maps showing:

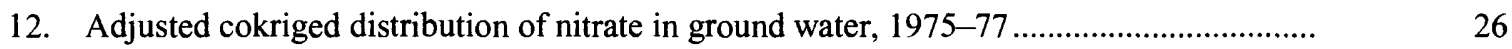

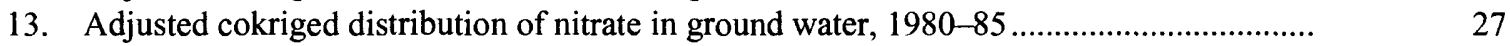

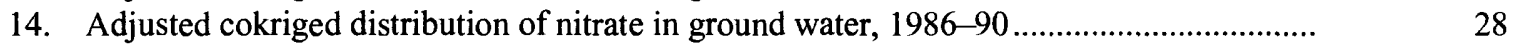

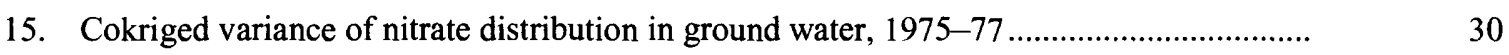

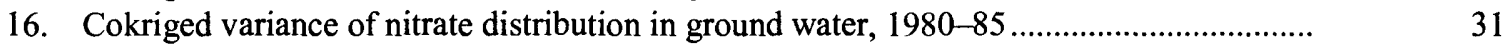

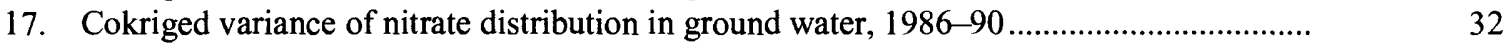

\section{TABLES}

1. Coefficients of global trends and drifts of transformed nitrate surfaces

2. Ranking of the top four statistical mapping methods, 1975-77, 1980-85, and $1986-90$...

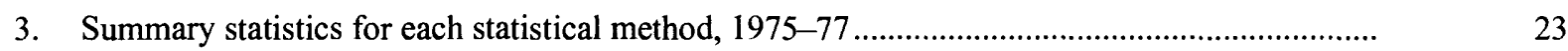

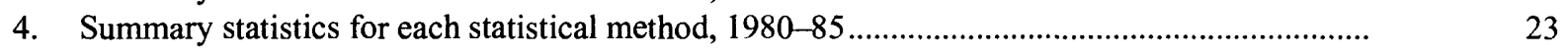

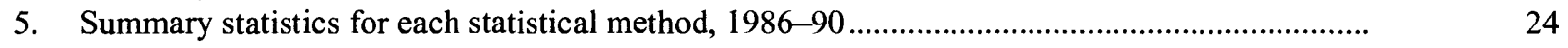

6. Average nitrate concentrations from cokriged maps for different land-use types.........................

7. Percentage of area on land-use map represented by indicated land use, and percentage of land underlain by ground water that contains nitrate concentrations greater than 10 milligrams per liter as $\mathrm{N}$

\section{CONVERSION FACTORS}

\begin{tabular}{rll}
\hline Multiply & By & To obtain \\
\hline millimeter $(\mathrm{mm})$ & 0.03937 & inch \\
meter $(\mathrm{m})$ & 3.281 & foot \\
cubic meter $\left(\mathrm{m}^{3}\right)$ & 0.0008 & acre-foot \\
kilometer $\left(\mathrm{km}^{2}\right)$ & 0.6214 & mile \\
square kilometer $\left(\mathrm{km}^{2}\right)$ & 0.3861 & square mile \\
\hline
\end{tabular}

In this report, temperature is reported in degrees Celsius $\left({ }^{\circ} \mathrm{C}\right)$, which can be converted to degrees Fahrenheit $\left({ }^{\circ} \mathrm{F}\right)$ by using the following equation:

$$
\mathrm{F}=1.8\left({ }^{\circ} \mathrm{C}\right)+32
$$

\section{ABBREVIATED WATER-QUALITY UNITS}

Chemical concentration and water temperature are given only in metric units. Chemical concentration in water is given in milligrams per liter $(\mathrm{mg} / \mathrm{L})$ or micrograms per liter $(\mu \mathrm{g} / \mathrm{L})$. Milligrams per liter is a unit expressing the solute mass (milligrams) per unit volume (liter) of water. One thousand micrograms per liter is equivalent to 1 milligram per liter. For concentrations less than 7,000 milligrams per liter, the numerical value is about the same as for concentrations in parts per million. 


\section{WELL-NUMBERING AND NAMING SYSTEM}

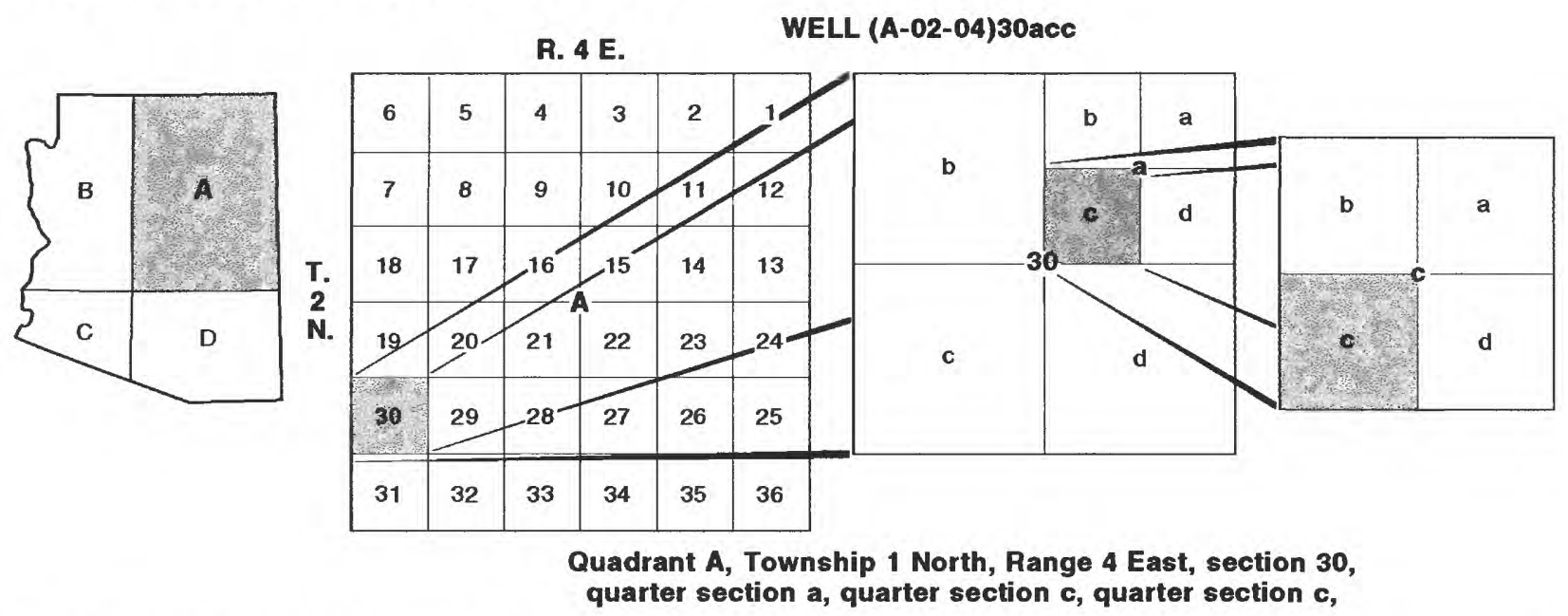

The well numbers used by the U.S. Geological Survey in Arizona are in accordance with the Bureau of Land Management's system of land subdivision. The land survey in Arizona is based on the Gila and Salt River meridian and base line, which divide the State into four quadrants and are designated by capital letters A, B, C, and D in a counterclockwise direction, beginning in the northeast quarter. The first digit of a well number indicates the township, the second the range, and the third the section in which the well is situated. The lowercase letters $a, b, c$, and $d$ after the section number indicate the well location within the section. The first letter denotes a particular 160 -acre tract, the second the 40 -acre tract, and the third the 10-acre tract. These letters also are assigned in a counterclockwise direction, beginning in the northeast quarter. If the location is known within the 10-acre tract, three lowercase letters are shown in the well number. Where more than one well is within a 10-acre tract, consecutive numbers beginning with 1 are added as suffixes. In the example shown, well number (A-02-04)30acc designates the well as being in the SW1/4, SW1/4, NE1/4, section 30, Township 2 North, and Range 4 East.

\section{VERTICAL DATUM}

Sea level: In this report, "sea level" refers to the National Geodetic Vertical Datum of 1929-A geodetic datum derived from a general adjustment of the first-order level nets of the United States and Canada, formerly called Sea Level Datum of 1929. 


\title{
Statistical Analysis of Nitrate in Ground Water, West Salt River Valley, Arizona
}

\author{
By A.E. Long, James G. Brown, and D.J. Gellenbeck
}

\section{Abstract}

Accurate estimates of the nitrate concentrations in ground water in west Salt River Valley are needed to better manage ground water affected by nitrate. Statistical analyses were done to establish the best statistical method to produce these estimates. Three sets of ground-water data for different time periods - 1975-77, 1980-85, and 1986-90 - were used to analyze spatial and temporal variations in concentrations of nitrate in ground water.

The use of inverse-distance squared weighting, radial-basis function, kriging, and cokriging were evaluated for estimating nitrate concentrations in ground water. From an analysis of the cross-validation results, cokriging maps resulted in the best estimates, and they were accepted as being the most reliable. Cross-validation results also indicated that nitrate cokriged best with magnesium for 1975-77 and 1986-90 and with calcium for 1980-85. Kriging results consistently were almost as reliable as any of the cokriging results. Because of the difficulties inherent in the cokriging process, kriging, although not optimal, was the fastest way to obtain reasonably good results.

In 1980-85, cokriged nitrate concentrations exceeded 20 milligrams per liter in a 12-square-kilometer area in Phoenix and Glendale and exceeded 10 milligrams per liter in a 280-square-kilometer area that extended to the Salt River. In 1986-90, nitrate concentrations along the entire reach of the Salt River in west Salt River Valley were less than 10 milligrams per liter and were smaller probably as a result of recharge from the Salt and Gila Rivers in 1983. Farther north in Phoenix and Glendale, the area in which nitrate concentrations exceeded 10 milligrams per liter expanded to 490 square kilometers for 1986-90. In Buckeye Valley, nitrate concentrations exceeded 10 milligrams per liter in an area of 300 square kilometers for $1980-85$ and 220 square kilometers for 1986-90. The measured decrease is likely the result of recharge from the Gila River in the early 1980's but possibly could be an artifact of the different data distributions associated with each data set. In the Phoenix area, cokriged nitrate concentrations for 1975-77 exceeded 10 milligrams per liter in a 290-square-kilometer area and exceeded 20 milligrams per liter in a 1.4-square-kilometer area.

\section{INTRODUCTION}

Nitrate concentrations in ground water from several areas of west Salt River Valley in central Arizona (fig. 1) exceed the maximum contaminant level (MCL) set by the U.S. Environmental Protection Agency (USEPA) of $10 \mathrm{mg} / \mathrm{L}$ of nitrate as N. As the use of ground water increases in this area to meet the increasing population, the management of ground water that has large concentrations of nitrate becomes more difficult. The population in this area has been increasing since the early 1900's, and in 1990, 2.1 million people lived in the Phoenix metropolitan area. In addition to being a major population center, large parts of the valley have been intensively farmed 


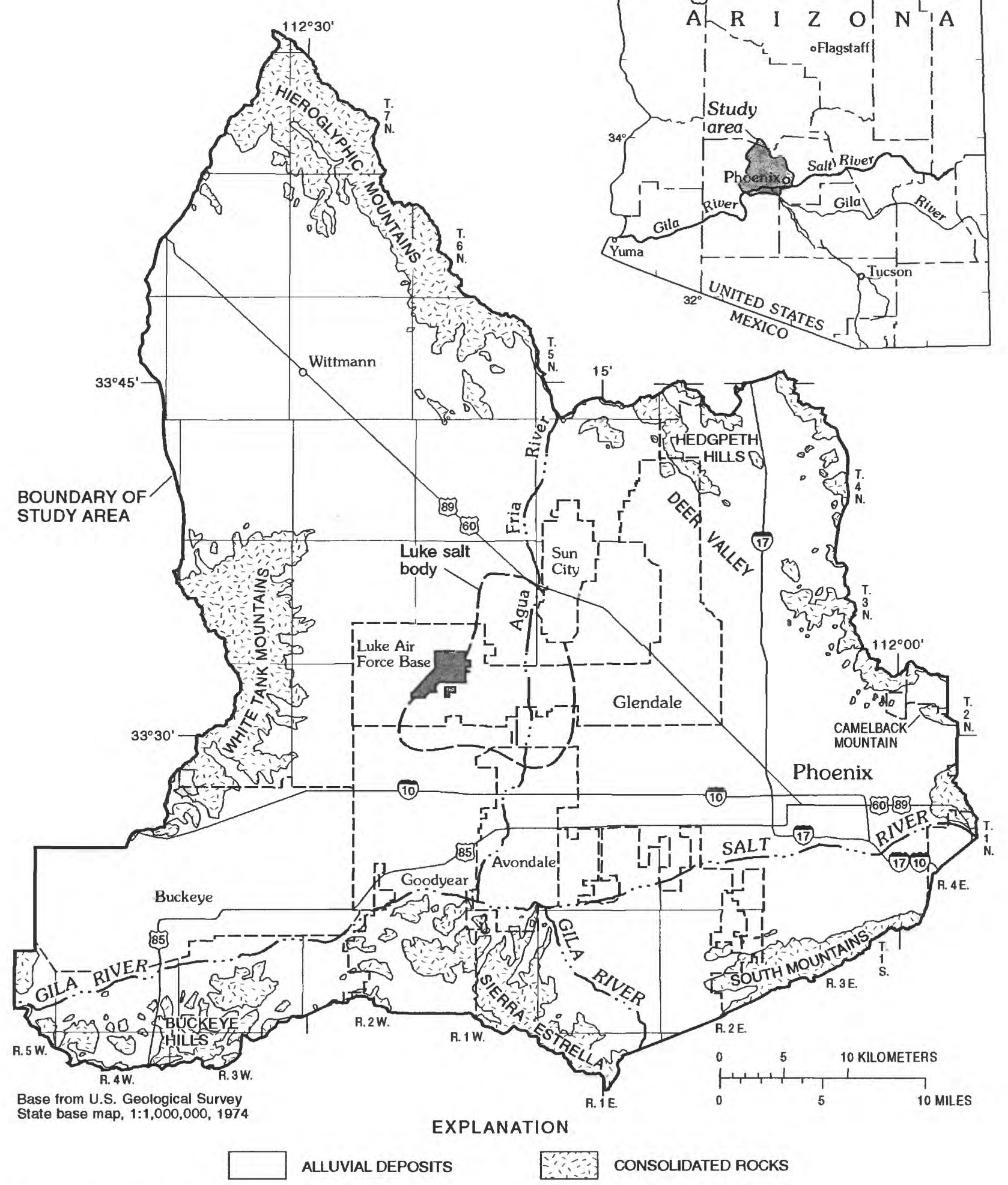

Figure 1. West Salt River Valley, Arizona. 
since the early part of the century. In some areas, the nitrate is derived from a natural source, and in other areas, nitrate is the result of one or more human activities (Maricopa Association of Governments, 1979, p. IV-9).

To better manage the ground-water resource in this area, accurate estimates of nitrate distribution and identification of nitrate sources are needed. In a response to this need, a project was developed in 1990 by the U.S. Geological Survey (USGS) in cooperation with the Arizona Department of Environmental Quality (ADEQ). The objectives of this project were to (1) develop a geochemical technique to identify sources of contaminants in ground water on the basis of the chemical and isotopic compositions of the ground water and suspected nitrate sources, and (2) establish the best statistical methods for unbiased and reproducible spatial estimates (maps) of nitrate concentrations in ground water.

\section{Purpose and Scope}

This report presents the results of statistical analyses done to establish the best statistical methods for unbiased and reproducible maps of nitrate concentrations in ground water. Three sets of ground-water data for different time periods-1975-77, 1980-85, and 1986-90-were used to analyze spatial and temporal variations in nitrate concentrations in ground water. Several statistical analyses were used before evaluating mapping methods including principal-component, correspondence, and variogram analyses. Only the results of the variogram analyses are presented in this report because the results from the other methods were of little value in assessing the relation of nitrate to other chemical constituents. Four mapping methods-inverse-distance squared weighting, radial-basis function, kriging, and cokriging-were evaluated for estimating nitrate concentrations in ground water. Discriminant analysis was used to identify land-use types on the basis of the isotopic composition of the underlying water. The results were unsuccessful and are not included in this report.

\section{Location and Geographic Setting}

West Salt River Valley is a large alluvial basin in central Arizona (fig. 1). Land-surface altitude of the valley floor ranges from about $730 \mathrm{~m}$ above sea level north of Wittmann to $240 \mathrm{~m}$ above sea level where the Gila River exits the basin southwest of Buckeye. The average daily maximum temperature in July is $40.5^{\circ} \mathrm{C}\left(105^{\circ} \mathrm{F}\right)$, and the average daily maximum temperature in December is $18.3^{\circ} \mathrm{C}$ $\left(65^{\circ} \mathrm{F}\right.$; Sellers and others, 1985). Rainfall in the valley averages $190 \mathrm{~mm} / \mathrm{yr}$ (Sellers and others, 1985) and occurs during two distinct periods. Frontal storms that originate in the Pacific Ocean produce rain during the winter, and local and sometimes intense thunderstorms produce rain during the monsoon season from July to September. In addition, dissipating tropical cyclones that originate in the tropical north Pacific occasionally cause widespread and intense rainfall in late summer or early autumn. The three major rivers in the valley-the Gila, Salt, and Agua Fria-normally are dry in the study area except during or following prolonged or intense precipitation.

\section{Previous Investigations}

Lee (1905) completed the first substantial investigation of the distribution, quantity, and quality of ground water in the Salt River Valley. More recently, Kam and others (1966) presented basic ground-water information for the Salt River Valley west of Phoenix. Brown and Pool (1989) described the lithologic, hydraulic, and waterquality characteristics of the hydrogeologic units that are found in west Salt River Valley. Kister (1974) defined the distribution of dissolved solids in the Salt River Valley. In the late 1970's and early 1980's, the Maricopa Association of Governments (MAG; Maricopa Association of Governments, $1978,1979,1981,1983$ ) produced a series of reports under Section 208 of the Water Pollution Control Amendments of 1972 that examined the chemical quality of ground water and sources of 
pollution in ground water in Maricopa County and included a map of nitrate distribution and discussion of possible sources of nitrate.

Salt River Project (SRP), which provides ground and surface water to the Phoenix metropolitan area, reported on trends in nitrate and other chemical constituents in ground water in the Salt River Valley east of the Agua Fria River (SRP, 1982; Smith, 1986). The Southwest Alluvial Basins, Regional Aquifer Systems Analysis (Swab/RASA) Project of the USGS evaluated many of the major ground-water basins in Arizona and bordering areas including the present study area (Robertson, 1991; Anderson and others, 1992). As part of the present study, Gellenbeck (1994) examined ground-water chemistry in areas of west Salt River Valley that contain large concentrations of nitrate and attempted to determine if one or a combination of two or more chemical or isotopic compositions could be used to identify individual nitrate sources.

\section{Data Compilation}

Three periods between 1975 and 1990 for which large data sets were available were selected for comparison and statistical analysis. The earliest period, 1975-77, included water-chemistry data from SRP wells that were obtained from SRP in computerized form. Paper copies of waterchemistry analyses compiled as part of the MAG studies provided information in areas outside SRP's service area. The water-chemistry analyses were obtained mainly from towns, cities, and irrigation districts. Data for the middle period, $1980-85$, consisted mostly of analyses from samples collected by personnel of the USGS and Arizona Department of Water Resources (ADWR). Data for the latest period, 1986-90, consisted of analyses of water from SRP wells in computerized form; data compiled from cities, towns, and irrigation districts; and samples collected for this project. The data sets for 1975-77 and 1986-90 consisted mostly of major-ion analyses; whereas, the data set for 1980-85 included many trace-element analyses. All non-USGS and non-SRP data were entered into the computer data base by hand, and the final data sets were checked by visual inspection and appropriate statistical analyses. Existing data were augmented by ground-water and surface-water samples collected in the summers of 1990 and 1991 (Gellenbeck, 1994).

Only analyses of water from wells for which the depth was known were used in the statistical analysis. Most were irrigation wells, and in most of them, the perforated interval also was known. The perforated intervals of all the wells used in this study ranged from 3.48 to $66.12 \mathrm{~m}$. Measured water chemistry represents a mixture of water from the entire perforated interval. Ionic balances were computed for each analysis; only those analyses with cation-anion differences, in milliequivalents per liter $(\mathrm{meq} / \mathrm{L})$, of less than 10 percent were used in the statistical procedures. Questionable values were compared with similar values obtained at other times to ensure the value was accurate.

A land-use map for 1973 was obtained from the USGS Earth Science Information Center in digital form and was converted to ARC format before analysis. A generalized land-use map for 1987 was generated by project personnel from aerial photographs (McLain Harbors Co., Inc., 1987) and converted into ARC format. Water-level data for selected wells were obtained from the USGS data base. Most of the water levels from the USGS data base were measured by ADWR personnel.

\section{Acknowledgments}

SRP; the Cities of Phoenix, Glendale, and Sun City; the Roosevelt Irrigation District; Buckeye Irrigation Company; Metropolitan Water District; Sunnyboy Water Company; and other smaller companies shared or contributed hydrologic and chemical data. Dr. Donald E. Myers, Department of Mathematics, University of Arizona, developed the cokriging method. In addition, Dr. Myers has been available for consultation throughout the project. 


\section{HYDROLOGIC SETTING}

West Salt River Valley is in the Basin and Range physiographic province of the United States. The Swab/RASA Project grouped basins in Arizona and adjacent areas on the basis of hydrologic and geologic characteristics. West Salt River Valley was included in the central basins group in which (1) ground-water inflow and outflow are a significant component of the basin water budget, (2) ground water generally occurs in unconfined conditions, and (3) stream alluvium, where saturated, contains and yields significant amounts of ground water (Anderson and others, 1992, p. 45).

\section{Hydrogeologic Units}

Materials that fill the basin and form the regional aquifer were deposited during the Tertiary and Quaternary periods, which were characterized by faulting and basin subsidence that formed the present-day topography. The following discussion is summarized largely from Brown and Pool (1989).

Deposits in the study area range in grain size from silt to clay and consist of alluvial fan, streambed, evaporite, and volcanic materials. The basin is bounded at depth and laterally by crystalline and other relatively impermeable rocks that range in age from Precambrian to Tertiary. These materials include granite, schist, volcanic rocks, and sedimentary rocks. Brown and Pool (1989, sheet 1) divided the materials that fill the basin into lower, middle, and upper units on the basis of lithologic and hydraulic characteristics.

Brown and Pool designated the lowest and oldest of the three deposits as the lower unit, and further subdivided that unit into upper and lower parts. The lower part of the lower unit includes moderately to well-cemented mudstone, siltstone, gypsiferous and anhydritic mudstone, sand, gravel, gypsum, anhydrite, and basalt flows. The lower part of the lower unit ranges in thickness from about $30 \mathrm{~m}$ near the basin margins to more than $3,300 \mathrm{~m}$ in the center of the basin. The Luke salt body, one of the world's largest deposits of terrestrially derived halite, occurs in the lower unit in the central part of the basin. The lower unit overlies and is in fault contact with a pre-basin and range sedimentary unit and the older materials mentioned earlier.

The upper part of the lower unit overlies the lower part and consists of materials similar to the lower part but is only weakly cemented and contains no halite. The unit is more than $330 \mathrm{~m}$ thick in a trough between Luke Air Force Base (LAFB) and the White Tank Mountains, where the base of the unit is more than $500 \mathrm{~m}$ below land surface. In Buckeye Valley, the unit is less than $160 \mathrm{~m}$ thick; the base of the unit in this area lies between 160 and $330 \mathrm{~m}$ below land surface.

Overlying the lower unit is the middle unit, which includes playa, alluvial fan, and fluvial deposits that range in grain size from clay to gravel. The middle unit generally is weakly cemented by calcium carbonate. The unit contains no evaporite or evaporitic deposits and is less dense than the lower unit. Like the lower unit, the middle unit was deposited in a closed basin. In the Sun City area, where the middle unit and upper part of the lower unit are coarse grained, the units are indistinguishable.

The upper unit overlies the middle unit throughout the basin and includes unconsolidated gravel, sand, and silt. The unit is coarsest and thickest along the Salt and Gila Rivers, where it contains more than 80-percent sand and gravel and is as much as $133 \mathrm{~m}$ thick. The upper unit was deposited after the development of throughflowing drainages in the basin and is the most permeable water-bearing unit in the basin.

\section{Occurrence and Movement of Water}

Streamflow in the basin is ephemeral and sporadic. Because of upstream storage and diversions, the Salt, Agua Fria, and Gila Rivers flow only when large amounts of precipitation result in runoff and (or) releases from upstream reservoirs. Before dams were built, the Salt River flowed perennially into the Salt River Valley (Lee, 1905, p. 121) and provided a continuous source of ground-water recharge. Under present conditions, significant recharge through river channels occurs only during reservoir releases. About $1.1 \times 10^{8} \mathrm{~m}^{3}$ of 
water infiltrated the channel of the Salt River from February 1978 to June 1980 (Mann and Rohne, 1983). Smaller streams in the area are naturally ephemeral and flow only during and following prolonged or intense rainfall. Recharge also occurs along the fronts of mountains that form the perimeter of the valley as water runs off impermeable rocks and infiltrates alluvial fans and other unconsolidated basin-fill materials. Recharge to the regional aquifer also occurs through unlined irrigation canals, from irrigation return flows, from excess irrigation water that infiltrates past the root zone, and downstream from where treated sewage effluent is discharged into river or creek channels. On the basis of tritium concentrations, Gellenbeck (1994) found that water within about $6 \mathrm{mi}$ of the Salt and Gila Rivers was recharged more recently than was water more than about 6 mi north of the Salt and Gila Rivers. The young age of the water probably was the combined result of recharge and application of excess irrigation water that infiltrated the root zone and eventually reached the water table.

Large-scale ground-water withdrawals from the regional aquifer have lowered water levels and have altered and locally reversed predevelopment ground-water flow directions. In T. 4 N., R. 1 E., ground-water levels declined as much as $50 \mathrm{~m}$ between 1945 and 1985 (Konieczki and Wilson, 1992, pl. 1). In 1923, the ground-water table generally conformed to the land surface (Anderson, 1968, p. 6). Ground water flowed from the Phoenix area southwest toward the Salt River. West of the Agua Fria River, flow generally was southward toward the Gila River (Anderson, 1968, pl. 1). In 1985 and 1992, ground water south of LAFB flowed to the northwest into a large water-table depression centered about $2 \mathrm{mi}$ west of LAFB (fig. 2; Brown and Pool, 1989). In 1985, ground water flowed north into another water-table depression in T. 4 N, Rs. 1 and 2 E. (Brown and Pool, 1989, fig. 2). By 1995, this depression had disappeared (fig. 2) probably because of recharge through stream channels and washes including the Agua Fria River (Hammett and Herther, 1995). In addition to complicating the analysis of the flow system, such reversals in flow direction also complicate the analysis of measured trends in water chemistry and movement of naturally occurring constituents and contaminants.

\section{Water Chemistry}

The measured distribution of dissolved chemical constituents in ground water in the study area is mainly the result of naturally occurring processes but has been altered by (1) large-scale ground-water withdrawals, (2) recharge of irrigation water and sewage effluent, and (3) infiltration of runoff from urban areas. Ground water in the valley has been contaminated locally by leaking underground storage tanks, from landfills, and from industrial chemicals such as trichloroethylene (TCE). In most of the study area, concentrations of metals were near or below detection limits.

\section{Distribution of Chemical Constituents}

The dissolved-solids concentrations in ground water from the basin are smallest near recharge areas and increase through reactions with aquifer materials as the water moves downgradient. Robertson (1991, p. C30) identified chemical reactions that controlled the natural evolution of ground water in alluvial basins in the southwest. Those that probably contribute dissolved solids to ground water in west Salt River Valley include:

- Dissolution of halite and gypsum (or anhydrite), respectively:

$$
\mathrm{NaCl} \rightarrow \mathrm{Na}^{+}+\mathrm{Cl}^{-},
$$

and

$$
\mathrm{CaSO}_{4} \rightarrow \mathrm{Ca}^{+2}+\mathrm{SO}_{4}^{-2}
$$

- Hydrolysis reactions involving calcite, potassium feldspar, and plagioclase feldspar, respectively:

$$
\begin{gathered}
\mathrm{CaCO}_{3}+\mathrm{H}_{2} \mathrm{O} \rightarrow \mathrm{Ca}^{2+}+\mathrm{HCO}_{3}^{-}+\mathrm{OH}^{-}, \\
\mathrm{KAISi}_{3} \mathrm{O}_{8}+8 \mathrm{H}_{2} \mathrm{O} \rightarrow \mathrm{K}^{+}+\mathrm{Al}^{+2} \\
+3 \mathrm{H}_{4} \mathrm{SiO}_{4}+4 \mathrm{OH}^{-}
\end{gathered}
$$

and 


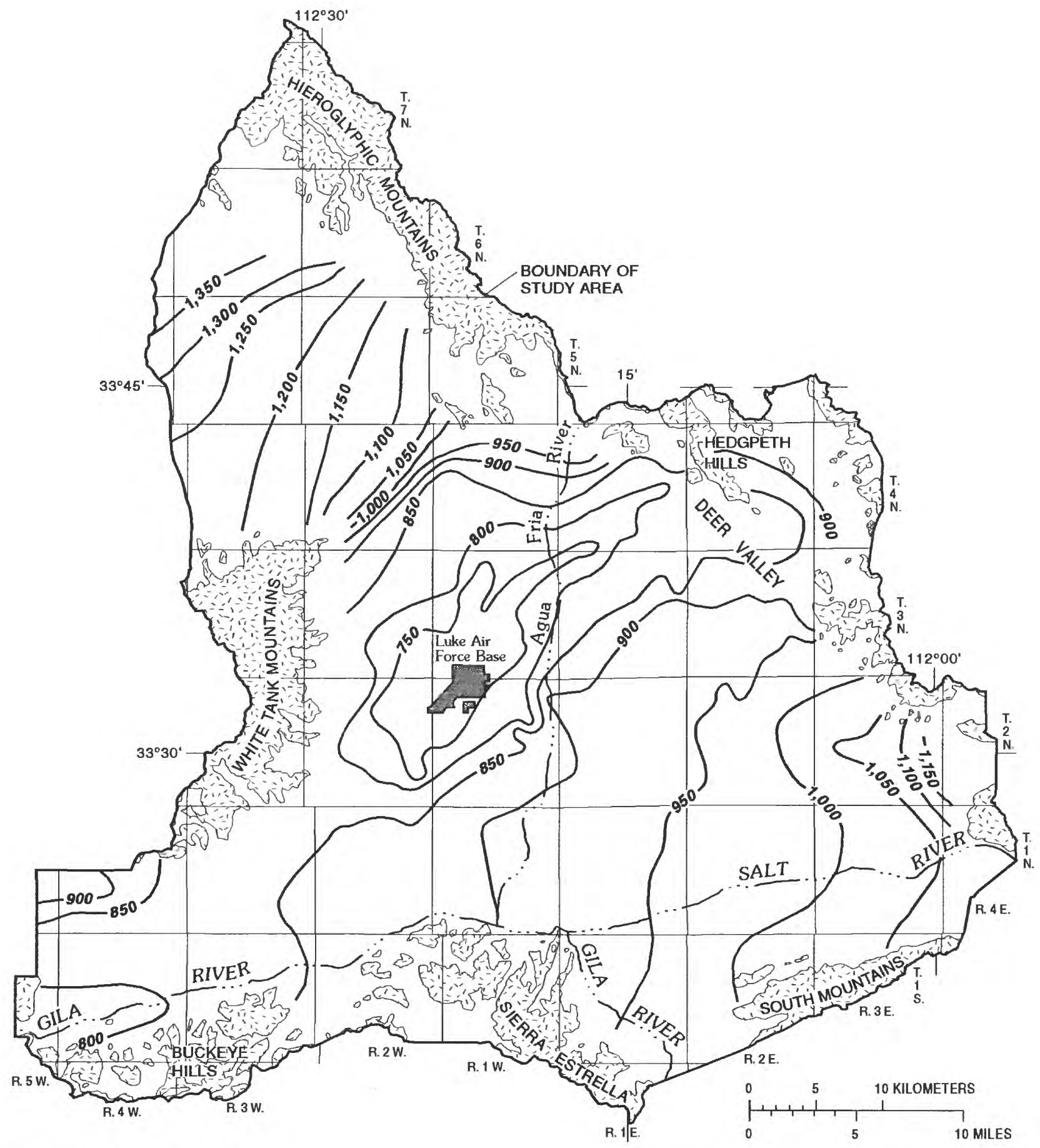

Base from U.S. Geological Survey State base map, 1:1,000,000, 1974

EXPLANATION

\begin{tabular}{|c|c|}
\hline & $\begin{array}{l}\text { - } 900 \text { - WATER-TABLE CONTOUR-Shows } \\
\text { althude of water table, 1992. Contour }\end{array}$ \\
\hline CONSOLIDATED ROCKS & evel \\
\hline
\end{tabular}

Figure 2. Altitude of the water table, west Salt River Valley, Arizona, 1992 (from Hammett and Herther, 1995). 


$$
\begin{aligned}
& \mathrm{Ca}_{0.45} \mathrm{Na}_{0.55} \mathrm{Al}_{1.45} \mathrm{Si}_{2.55} \mathrm{O}_{8}+8 \mathrm{H}_{2} \mathrm{O} \rightarrow 0.45 \mathrm{Ca}^{+2} \\
& +0.55 \mathrm{Na}^{+}+1.45 \mathrm{Al}^{+3}+2.55 \mathrm{H}_{4} \mathrm{SiO}_{4}+5.8 \mathrm{OH}^{-}
\end{aligned}
$$

- Cation-exchange reactions in water containing large concentrations of dissolved solids (Robertson, 1991, p. C78):

$$
\begin{gathered}
\mathrm{Ca}^{+2}+2 \mathrm{Na}_{\mathrm{ex}} \rightarrow \mathrm{Ca}_{\mathrm{ex}}+2 \mathrm{Na}^{+}, \\
\mathrm{Ca}^{+2}+2 \mathrm{~K}_{\mathrm{ex}} \rightarrow \mathrm{Ca}_{\mathrm{ex}}+2 \mathrm{~K}^{+},
\end{gathered}
$$

and

$$
\mathrm{Ca}^{+2}+2 \mathrm{Mg}_{\mathrm{ex}} \rightarrow \mathrm{Ca}_{\mathrm{ex}}+\mathrm{Mg}^{+2}
$$

In 1980-85, dissolved-solids concentrations ranged from less than $400 \mathrm{mg} / \mathrm{L}$ in T. $4 \mathrm{~N}$. to more than $4,000 \mathrm{mg} / \mathrm{L}$ in Buckeye Valley (Brown and Pool, 1989, fig. 13). As more solids dissolve in the water, the relative proportion of major ions changes. Water in the study area containing less than $400 \mathrm{mg} / \mathrm{L}$ of dissolved solids is a mixed type, which means that no individual cation or anion contributes more than 50 percent, in milliequivalents per liter, to the total of each. Water containing large concentrations of dissolved solids is a sodium chloride type (Brown and Pool, 1989, fig. 15, table 2). The linear arrangement of cation data on a Piper diagram of ground water in the valley (fig. 3 ) represents the general downgradient increase in sodium concentrations as ground water moves southward and westward toward Buckeye Valley. Most of the samples in which sodium and potassium in combination make up more than 50 percent of the total cation concentration (the lower-right quarter of the cation triangle) are from the western part of the valley.

A vertical increase in dissolved-solids concentrations in the valley is controlled largely by the presence or absence of evaporites in the lower unit. In areas where evaporites are absent, dissolvedsolids concentrations generally are lower in the lower part of the lower unit than in overlying materials. In areas where evaporites are present, such as near the Luke salt body, dissolved-solids concentrations generally increase with depth in the lower unit (Brown and Pool, 1989, sheet 5). The concentration of dissolved solids in ground water has varied through time. From 1965 to 1985 , dissolved-solids concentrations decreased along the Salt River and in the Phoenix area but increased in the Glendale area (Salt River Project, 1982, p. 10-5).

\section{Nitrate}

Concentrations of dissolved nitrate that exceed the MCL of $10 \mathrm{mg} / \mathrm{L}$ as $\mathrm{N}$ (U.S. Environmental Protection Agency, 1991) have been recognized in ground water in the basin since the turn of the century (Lee, 1905. p. 137-142). As of 1990, significant areas of the valley were underlain by ground water that contains more than $10 \mathrm{mg} / \mathrm{L}$ of nitrate (reported as $\mathrm{N}$ ). Only some of the nitrate in ground water is of natural origin. Other known and potential sources included irrigation-return flows, nitrogen fertilizers, treated sewage, and concentrated animal-feeding operations. Nitrate concentrations generally were less than $10 \mathrm{mg} / \mathrm{L}$ near the mountain-front recharge areas, north of the White Tank Mountains, and in the Phoenix area. Ground water containing more than $10 \mathrm{mg} / \mathrm{L}$ of dissolved nitrate was near Glendale and in Buckeye Valley although the distribution varied.

Significant variations in nitrate concentrations in water from wells commonly occur in west Salt River Valley. Some limitations of the data used in the statistical analyses are the result of variation of nitrate concentrations in ground water with time. These variations occur over short (hours) and long (years) time scales (fig. 4), cannot be easily explained, and may limit the ability to map nitrate concentrations in the ground water in the study area. Samples that represent a mixture of ground water drawn from multiple zones, especially in wells with large screened intervals, might be one of the causes of these variations. The chemical analyses used in the statistical procedures have been reviewed to ensure that the analyses are acceptable. The possible influence of variation due to hydrogeologic effects, such as mixing of ground water from different zones in the aquifer, has not been considered; nor is it accounted for in the variance of the samples as a component of the measurement error or measured uncertainty. 


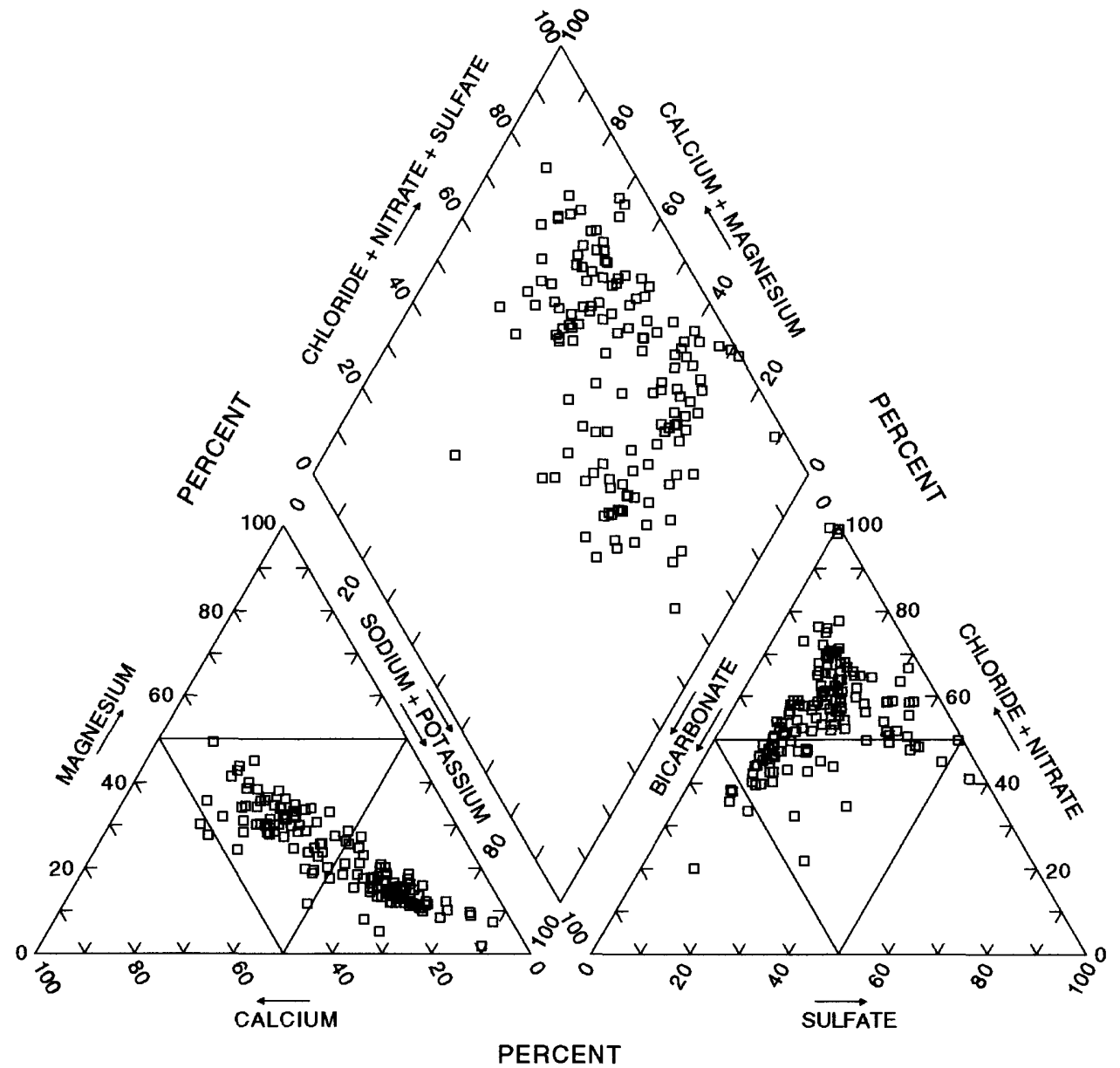

Figure 3. Relative compositions of ground water, in percent, west Salt River Valley, Arizona, 1986-91 (modified from Gellenbeck, 1994).

\section{METHODS OF STATISTICAL ANALYSIS}

A variety of statistical methods was used to examine the nitrate distribution in the study area, to explore the relation among nitrate and other chemical constituents and other variables, such as land use, and to determine the method that would produce the most reliable map of nitrate distribution in ground water in the study area. Variogram analysis was used to explore the relation of nitrate to other chemical constituents and to other factors, such as land use, and to determine the factors or chemical constituents that would be best suited for cokriging with nitrate. The distribution of nitrates was mapped using inversedistance squared-weighting estimates, radial-basis function, kriging, and cokriging. Kriging and cokriging (the associated multivariate version of kriging) typically are considered to be statistical methods. Because cokriging includes kriging as the univariate case, this report generally will refer to cokriging only. Kriging was developed first and then generalized to cokriging.

Geostatistics is a branch of statistics dealing with variables that show spatial and (or) temporal correlation. Mapping a spatially correlated data set involves estimating data at given sites from known values at nearby sites. The weight attributed to a given site with a known value generally is a decreasing function of distance from the site at which the estimate is desired. Geostatistics were used in this study to determine the usefulness of chemical constituents in addition to nitrate for enhancing and extending the regional estimation 


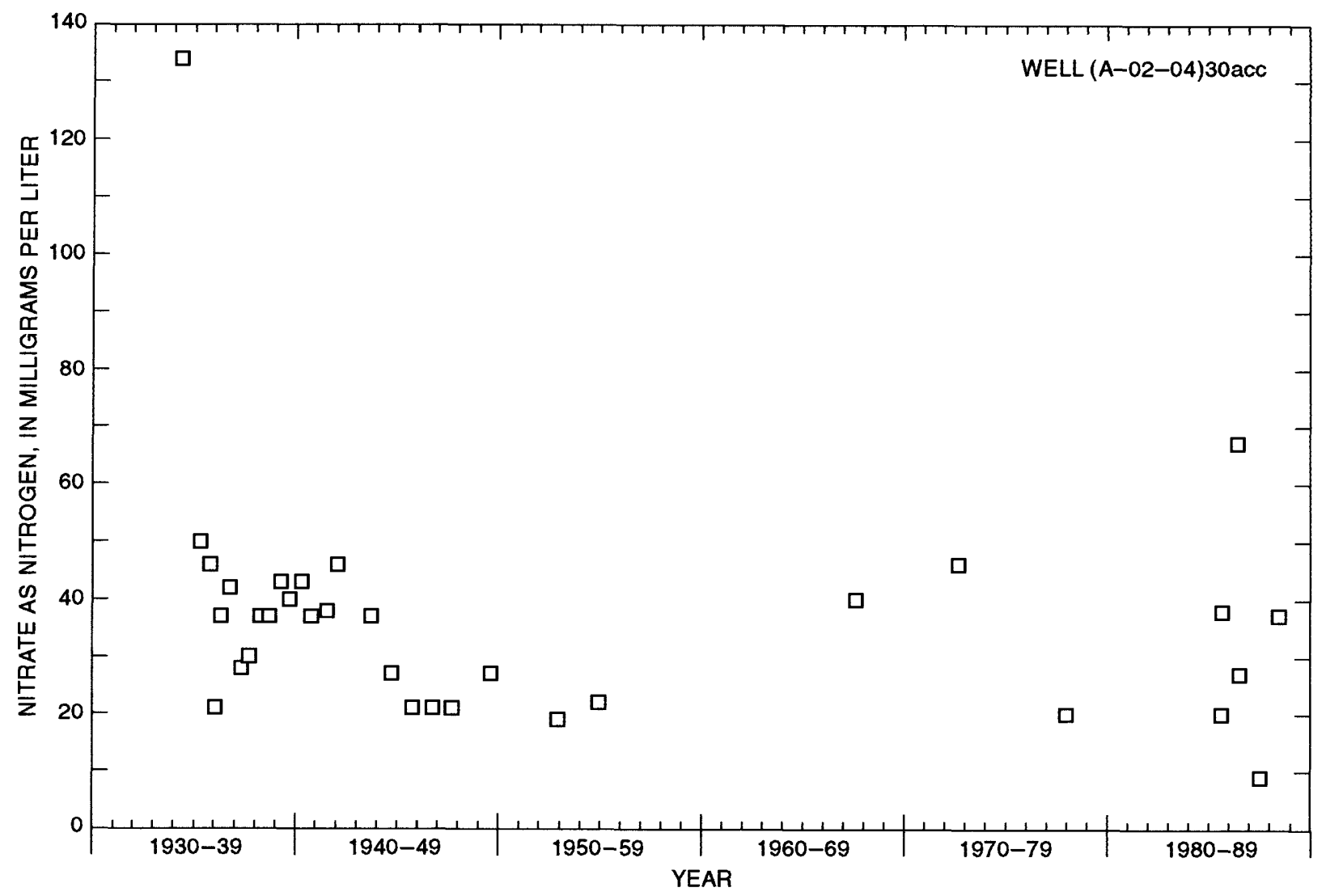

Figure 4. Nitrate concentration at well (A-02-04)30acc, west Salt River Valley, Arizona, 1934-88.

(the map of nitrate distribution). First, however, selected statistical transformations were applied to the data in order to make the data sets conform to the assumptions required by the multivariate analyses and interpolation techniques just mentioned.

Cokriging is a technique that is unbiased in its estimates and minimizes the estimation variance among linear estimators. Cokriging uses information from the sampled data values of the chemical of interest plus those of other, associated chemicals to arrive at the weights used for the various components of the data vectors of neighbors of the point at which the estimate is to be given. One of the objectives of cokriging is to improve estimates of covarying components and to reduce estimation uncertainty through coestimation.

\section{Data Treatment and Transformation}

When dealing with large data sets it is necessary to consider what data reduction and manipulation is desirable or possible. The chemical data sets used in this analysis required several mathematical manipulations before statistical analysis. In many analyses, one or more chemical constituents occurred at concentrations less than the minimum reporting level (MRL). The manner in which these data, known as censored data, are treated depends on the purpose and type of the analysis, the nature of the censored data, and the hydrologic or chemical intuition of the investigator. Some investigators have generated summary statistics using an assumed distribution for the censored data (Helsel, 1990). Others have used the MRL detection limit or some fraction thereof, or have simply omitted the censored data. In this study, censored values were replaced by the value of the MRL. Although the reported values 
remained small in these cases, the actual value is overestimated. Because the data came from a variety of sources and included data for multiple years, the MRL's varied spatially and temporally. In addition, many analyses included determinations for major ions only and did not include values for trace metals or other minor constituents such as fluoride. Constituents that did not have values for every analysis therefore were excluded from some of the statistical analyses.

In order to obtain variables that are approximately normally distributed, the hydrologic data were $\log$ transformed before performing many types of statistical analyses. An unfortunate side effect of such data transformations is that linear and unbiased estimators are not unbiased for the moments of the original data but rather only for the moments of the transformed data. Simply transforming log-transformed data back into its original form potentially can introduce bias to the estimate. The technique used in this study attempted to remove any bias that may have been introduced.

Following log transformation, the variables of interest were normalized to a mean of 10 and a variance of 1 (they were centered on a mean of 10 , rather than zero, to allow for the use of correspondence analysis). This normalization also made the variogram analysis more intuitive and easier to understand and had no adverse effects because normalization is a linear process. The transformed variables generally appeared to be normally distributed.

As mentioned above, the methods considered in this analysis were all carried out on the log-transformed nitrate values. This means that the data were retransformed in order to produce the maps in the original units. Because no standard method exists for removing the bias in a universally kriged interpolation, the following procedure was devised to remove the bias. After results were computed using the log-transformed data, the cross-validation results were exponentiated. The cross-validation mean of the exponentiated values then was compared with the real data mean to get a multiplicative-scale factor (the bias adjustment). The nontransformed nitrate estimates shown on the maps were produced by exponentiating and multiplying by the scale factor (a) using the equation:

$$
\gamma=(a) \bullet \exp (x)
$$

where

$$
\begin{aligned}
& \gamma=\text { nontransformed nitrate estimate, } \\
& a=\mathrm{a} \text { nitrate value, and } \mathrm{x}_{\mathrm{i}}^{\prime} \text { equals } \mathrm{a} \\
& \text { cross-validated nitrate value, and } \\
& x=\text { a transformed nitrate estimate. }
\end{aligned}
$$

\section{Variogram Analysis}

Variogram analysis is a statistical technique developed to account for the variability of values as a function of intersample distance. A measure of the correlation between variables as a function of distance and direction is helpful when determining which variables to cokrig with nitrate values. Variogram analysis was used to determine which of approximately 36 sampled variables would be most useful for cokriging nitrate values. As already mentioned, some variables were eliminated on the basis of other criteria; however, many variables needed to be verified. Variogram analysis is a nonstandard analysis and can be extremely useful for estimating the geographic distributions of chemical constituents in water and many other environmental variables. Variogram analysis quantifies the correlations that exist between a single variable at different sites, the range over which a variable is correlated, and can be used to identify directional trends in the data. This concept has been extended to quantify the correlations of different variables at different sites through the use of what are known as covariograms. Covariogram analysis determines similarities between ncighbors and between variables.

In estimating the nitrate concentration at a given unsampled location, information from neighboring wells is weighted. In a well-correlated field, neighbors allow better estimates of the values at unsampled locations by giving more credence to those sites that are most similar to the site of 
interest. The purpose of variogram analysis and covariogram analysis is to determine the amount of spatial correlation and autocorrelation in a data set.

A principal statistical assumption is that the relation between neighbors and variables is a function of distance and direction. In kriging, the variogram is used to perform this function. The variogram simply is a spatial decomposition of the variance. From the variogram, distances and directions for which variances of the variable of interest are low can be determined. Where the variances are low, values are more reliable and are weighted more heavily.

Variograms are characterized by a model type, range, nugget, and sill, as well as by the presence or absence of drift. The model type is the mathematical function that best characterizes the distribution of points that make up the variogram. The nugget indicates the amount of noise in the data at the smallest lag or the extent to which the sampled intervals exceeded the smallest distance scales. The range is the distance over which the variable or variables can be correlated. Beyond this distance, the variogram ceases to increase and forms a flat region called a sill, which generally is equal in magnitude to the variance around the average value (Davis, 1986). At distances less than the range, the variance describes the relation between points separated by specified increments or distances.

Experimental variograms of the variables of interest are inspected for similar features that may represent similar geochemical processes that occur for nitrate and other variables. Ideally one or more cross variogram(s) of nitrate with another variable will indicate high (in absolute value) spatial correlation in the first few lags, and a smoothly varying relation (rather than an irregular relationpositive to negative jumps). Because the cross variogram is a spatial decomposition of the correlation between the variables, the cross variogram will be predominantly positive, and the sill value will equal the covariance. If such features are found in the variogram and cross variogram with nitrate for a particular variable, that variable probably can be used to estimate nitrate with the cokriging procedure.
Because variogram analyses (historically done by visual inspection) and associated data manipulations take a significant amount of time, a data-driven program was developed to do a preliminary analysis and to provide preliminary estimates on the basis of kriging and a variety of cokriging. The program was written to model the variogram by a least-squares technique using an error function described by Cressie (1985). After the data are entered, the program ultimately produces a series of maps by proceeding through most of the analyses represented in figure 5. This program was tested against the work of Chbouki (1992). Chbouki reported that the program actually improved on the modeling that he had done using Geo-EAS (Englund and Sparks, 1991) from the standpoint of the ability to interpret the crossvalidation statistics (Nabil Chbouki, graduate student, University of Arizona, oral commun., 1992).

Examining and modeling the variograms and cross variograms are a pairwise multivariate analysis on the chosen set. The variograms generate a set of graphs, which must be modeled with conditionally negative definite functions. Cross variograms are subject to different rules and must satisfy a Cauchy-Schwartz condition (Goovaerts, 1994) when related to the variograms of the variables. The Cauchy-Schwartz condition, when written in terms of variograms (Long, 1994), is

$$
\left|\gamma_{i, j}(h)\right| \leq \sqrt{\gamma_{i, i}(h) \gamma_{j, j}(h)},
$$

where

$$
\begin{aligned}
\gamma_{\mathrm{i}, \mathrm{j}}(h) & =\text { cross variogram of variables }_{i} \text { and }_{\mathrm{j}} \\
\gamma_{\mathrm{l}, \mathrm{l}}(h) & =\text { variogram of variable }_{\mathrm{j}}, \\
\gamma_{\mathrm{j}, \mathrm{j}}(h) & =\text { variogram of variable }_{\mathrm{j}}, \text { and } \\
h & =\text { distance between data points. }
\end{aligned}
$$

\section{Inverse-Distance Squared Weighting}

Inverse-distance squared weighting belongs to a class of estimating techniques known as kernel methods. Historically, kernel methods were 


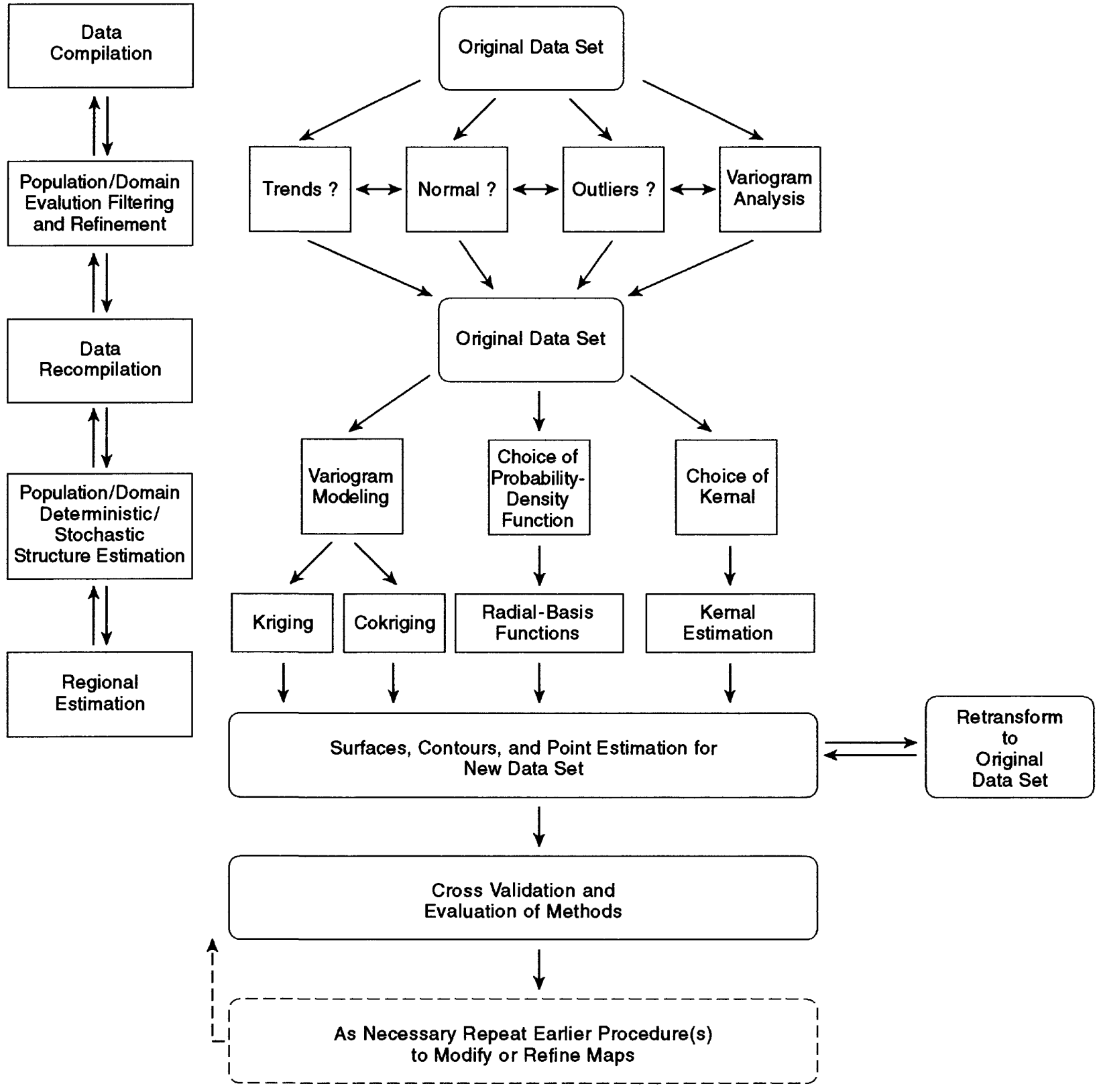

Figure 5. Statistical transformations and analyses used on water-chemisty data, west Salt River Valley, Arizona.

employed whenever estimation or interpolation of a data set was needed. In this study, inversedistance squared weighting was used. This method takes into account the distance between the location of the point to be estimated and a specified number of sample points. Closer samples are given more weight; each sample is assigned a weight inversely proportional to the square of the distance to the point to be estimated. The weights are normalized so that the weights for each estimated point sum to one:

$$
\hat{v}=\frac{\sum_{i=1}^{n} \frac{1}{d^{2}} \cdot v_{i}}{\sum_{i=1}^{n} \frac{1}{d^{2}}},
$$


where

$$
\begin{aligned}
\hat{v} & =\text { estimated value, } \\
d & =\begin{array}{l}
\text { distance of sample } i \text { from the esti- } \\
\text { mated point, }
\end{array} \\
n & =\begin{array}{l}
\text { specified number of samples to be } \\
\text { used in each estimate, and }
\end{array} \\
v_{i} & =\text { value of sample } i .
\end{aligned}
$$

The nature of this method is such that as distance from the data increases, the weights converge to a single value, which means that the estimate will be given by the mean of the data. In order to account for any spatial trend, kernel methods require that the trend be removed separately and then reintroduced into the estimates. This method is still widely used because it is easy, fast, well conditioned, and reliable. The reliability of these methods, however, is limited by the small number of points used to estimate a particular variable and because the choice of kernel function generally is arbitrary and does not take the sampling pattern into account. Methods, such as kriging and cokriging, have the potential to improve the reliability of estimates.

\section{Kriging, Cokriging, and Radial-Basis Functions}

With the advent of the computer and better and faster algorithms for the solution of linear systems, methods based on some sort of optimization scheme became available. Kriging, cokriging, and radial-basis function use information from all neighbors at once rather than sequentially as in the kernel case. This approach allows for adjustment of the sampling pattern because that pattern may overemphasize certain regions of the space, which would bias the results in favor of the dynamics of those regions.

Several varieties of kriging and cokriging have been developed. Simple kriging assumes a known mean, and ordinary kriging estimates the mean from the available data. These two forms are applicable only if the variable being mapped is stationary, which means that the variable exhibits no drift. Universal kriging estimates the drift, or mean surface, and so can be applied to a data set in which the mean varies from location to location.
Universal kriging also requires fewer assumptions because a local drift surface for each point is not required.

Ordinary and universal kriging may be local, if estimates are based on a moving neighborhood of data points, or global, if all data points are used in each estimate. One advantage of global, rather than local, kriging or cokriging is that if an estimate is desired at an additional point that was not originally calculated, a simple vector product will give the estimate. Another advantage is that the drift surface will be global-universal kriging or cokriging with a local neighborhood produces local and discontinuous drift surfaces. In the event that many variables are used in a global estimation, using principal-component analysis or linear regression on the associated variables to select that single compound variable that best correlated with nitrate might be considered. Then the variable of interest and the best surrogate variable can be used in a two-variable cokriging system.

Kriging, cokriging, and radial-basis function depend on solutions of large linear systems of equations, which make them increasingly unstable as the amount of data increases. For both radial-basis function and kriging, the size of the linear system is $N$ by $N$, where $N$ is the number of data points. Cokriging, while theoretically preferable to kriging, currently depends on linear systems that are $v N$ by $v N$, where $v$ is the number of variables used in the process. The size of the cokriging linear system, therefore, goes up quadratically in the number of variables. When dealing with such a system, it is essential to be aware of the condition of the covariance matrix. The condition of a random-covariance matrix goes up as the cube of the size, so the condition of the cokriging system goes up as the sixth power of the number of variables.

The singular-value decomposition solver used for kriging and cokriging in this investigation gives the condition as the ratio of the largest and smallest singular values (Long, 1994). When the condition (or ratio) is high, the results are more likely to be unreliable (ill conditioned). An ill-conditioned estimator is undesirable because as the amount of data or information available for use increases, the estimator gets worse, which is contrary to intuition and common sense. The condition of the matrix is but one factor that contributes to the reliability of a 
particular estimate. An estimate made using a well-conditioned matrix can still be unreliable because of other factors such as a large variance. Obtaining a reliable estimate using an illconditioned matrix, however, is for all intents and purposes impossible.

The problem generally is solved by restricting the number of neighbors used in the estimate at an unsampled location to some small number and using the nearest ones for an isotropic model or those that the data indicate will covary best with the location of interest in the anisotropic case. Usually the weights assigned to more distant points fall off rapidly; therefore, those points are set to zero. This process is called the moving neighborhood approach and acts like a filter that goes from site to site and selects specific neighbors for the estimation. The size and shape of that filter are best determined empirically from the variogram analysis of the data set. One typical choice is to take the neighborhood size from the variogram range perhaps on the basis of the assumption that weights on sites beyond the range distance are small.

In order to deal with limitations in matrix sizes and at the same time make simultaneous use of the possible correlation of more than one variable with nitrate, an artificial variable made up of a combination of two or more single variables was used. This process was attempted using linear regression.

Another method of reducing the data to a single linear combination is principal-component analysis. In this case, it is not assumed as is done with linear regression that nitrate is a response variable and is effectively assumed to have been measured more accurately than other variables. An attempt was made to find a linear combination of all the data that best explains the major proportion of the variance in the data. This linear relation then was inverted to get a composite (or surrogate) regression variable for nitrate.

When mapping any type of geographic data, it is essential to first determine (1) if a trend exists that must be removed and (2) if there are multispatial domains that must be treated separately. This determination is related to the stationarity of the data, which is a measure of how the data are distributed on a site-wise basis. If the data are strongly stationary, then all points may be considered as coming from the same distribution. If the data are not stationary, then it may be necessary to separate the data into subsets and remove a trend before mapping, or simply remove the trend and avoid having to separate the data. The data were consolidated into a single region, and universal cokriging (a global-estimation process that removes any trend) was done for estimation.

Strong stationarity requires that the mean of the data be constant and that covariances exist and depend only on the distance. Because neither of these criteria were met, a weaker form of stationarity, called the intrinsic hypothesis, was applied. The intrinsic hypothesis states that the difference of data values is stationary. Differences between data values are used in variogram analyses.

Another solution to the problem of nonstationarity was to remove the offending trend, although the trend had to be identified first. The trend represents information that might be useful, especially because trends represent regional, deterministic processes. In trend-surface analysis, a best-fit polynomial function is found for the data often by least squares. A linear estimator of the form is assumed:

$$
Z_{x}(x)=\sum_{i=1}^{n} b_{i} f\left(\left\|x-x_{i}\right\|\right)+\sum_{i=0}^{p} a_{i} p_{i}(x),
$$

where

$$
\begin{aligned}
& Z_{*}(x)=\text { estimated value of } Z \text { at } x, \\
& b_{i} f=\text { weighted variogram values, } \\
& a_{i}=i \text { weight for the } i \text { drift function at } \\
& \text { location } i, \text { and }
\end{aligned}
$$

Trend is obtained by performing a linear regression of the data on the functions used. In this study, linear regression was done on polynomial functions, for example the polynomial trend of second degree. The coefficients of the polynomials and weights are obtained in the estimation process, and the resultant $p^{\text {th }}$ degree polynomial is known as drift. Drift, as defined in this report, is the mean surface of the underlying process and is estimated by universal kriging (equation 10). Drift differs from trend in that the coefficients of the basis 
functions are obtained at each location being evaluated in universal kriging. The drift and trend generally do not agree but may be close.

In general, a northeast to southwest trend existed for increasing nitrate, and this trend coincided with the direction of flow of the Agua Fria and Salt Rivers (table 1). No relation is implied between the trend and direction of river flow by this interpolation technique.

\section{STATISTICAL ANALYSIS OF NITRATE IN GROUND WATER}

A variety of statistical techniques were used to analyze the spatial distribution of nitrate in west Salt River Valley and to learn more about how nitrate is related to or possibly controlled by other chemical constituents and land use. Variogram analysis revealed a somewhat random distribution for nitrate in all three data sets. Four methods were used to produce maps of contoured nitrate distribution-inverse-distance squared weighting, radial-basis function, kriging, and cokriging. Local universal kriging and cokriging with a quadratic-drift term were used in this analysis because the data appeared to have an increasing trend to the southwest. The maps produced by each method were compared using point-wise cross validation. Cokriging and kriging methods were found to be the best for these data sets, and the map produced from the cokriging procedure was used to produce the final maps for this study.

\section{Variogram Analysis}

Variogram analysis indicated that, in contrast to the other variables, nitrate was moderately coherent over a short range with a large nugget. In terms of kriging and cokriging of nitrate, this is undesirable because it means that the nitrate concentration at a given location depends little on values at other sample points. As a result, little additional weight can be placed on values of closer neighbors to estimate the nitrate value at a given location. This characteristic nature may be in part because nitrate in the study area results from nonpoint-source contamination from human activities (Goovaerts, 1992).

The sample cross-variogram matrix (fig. 6) can be used to determine the amount of relatedness between variables at different locations. The covariance of nitrate with any other variable reflects the degree to which nitrate and this other variable are related. The scaled cross variograms (fig. 7) indicate that there is little coherence between nitrate and other variables. Magnesium, calcium, and the linear-regression variable have cross variograms that indicate significant correlation with nitrate (fig. 7). All three are high initially although linear regression is slightly higher than calcium or magnesium. Oddly enough, however, the calcium variable ultimately performed poorly in cokriging. The magnesium and linear-regression variable correlate with nitrate much better than the remaining variables.

The sample variograms and cross variograms for the three data sets and the models that were used in the kriging and cokriging process are shown in figures 8-10. Of particular interest is the change in the forms of the nitrate variograms over

Table 1. Coefficients of global trends and drifts of transformed nitrate surfaces

[ $\mathrm{x}$, distance in east (positive values) or west (negative values) direction from origin; $\mathrm{y}$, distance in north (positive values) or south (negative values) direction from origin; origin at $33^{\circ} 22^{\prime} 38^{\prime \prime}$ latitude, $112^{\circ} 18^{\prime} 19^{\prime \prime}$ longitude. $\mathrm{km}$, kilometer; $\mathrm{km}^{2}$, square kilometer]

\begin{tabular}{|c|c|c|c|c|c|c|c|}
\hline Year & Type & Constant & $\begin{array}{c}x \\
(\mathbf{k m})\end{array}$ & $\underset{(\mathbf{k m})}{\mathbf{y}}$ & $\begin{array}{c}\mathrm{x}^{2} \\
\left(\mathrm{~km}^{2}\right)\end{array}$ & $\begin{array}{c}x y \\
\left(\mathbf{k m}^{2}\right)\end{array}$ & $\begin{array}{c}\mathrm{y}^{2} \\
\left(\mathrm{~km}^{2}\right)\end{array}$ \\
\hline \multirow{2}{*}{1977} & Trend: & 9.9020 & -0.0403 & 0.0418 & 0.0005 & 0.0034 & -0.0028 \\
\hline & Drift: & 10.4611 & -.0102 & .3173 & -.0005 & -.0009 & .0009 \\
\hline \multirow{2}{*}{1985} & Trend: & 10.2990 & -.0082 & .0172 & -.0003 & .0009 & -.0015 \\
\hline & Drift: & 9.6936 & .0049 & .0583 & -.0002 & -.0005 & -.0022 \\
\hline \multirow{2}{*}{1988} & Trend: & 9.6770 & -.0351 & .1005 & -.0004 & .0029 & -.0037 \\
\hline & Drift: & 9.7099 & -.0133 & .0878 & -.0003 & .0016 & -.0034 \\
\hline
\end{tabular}



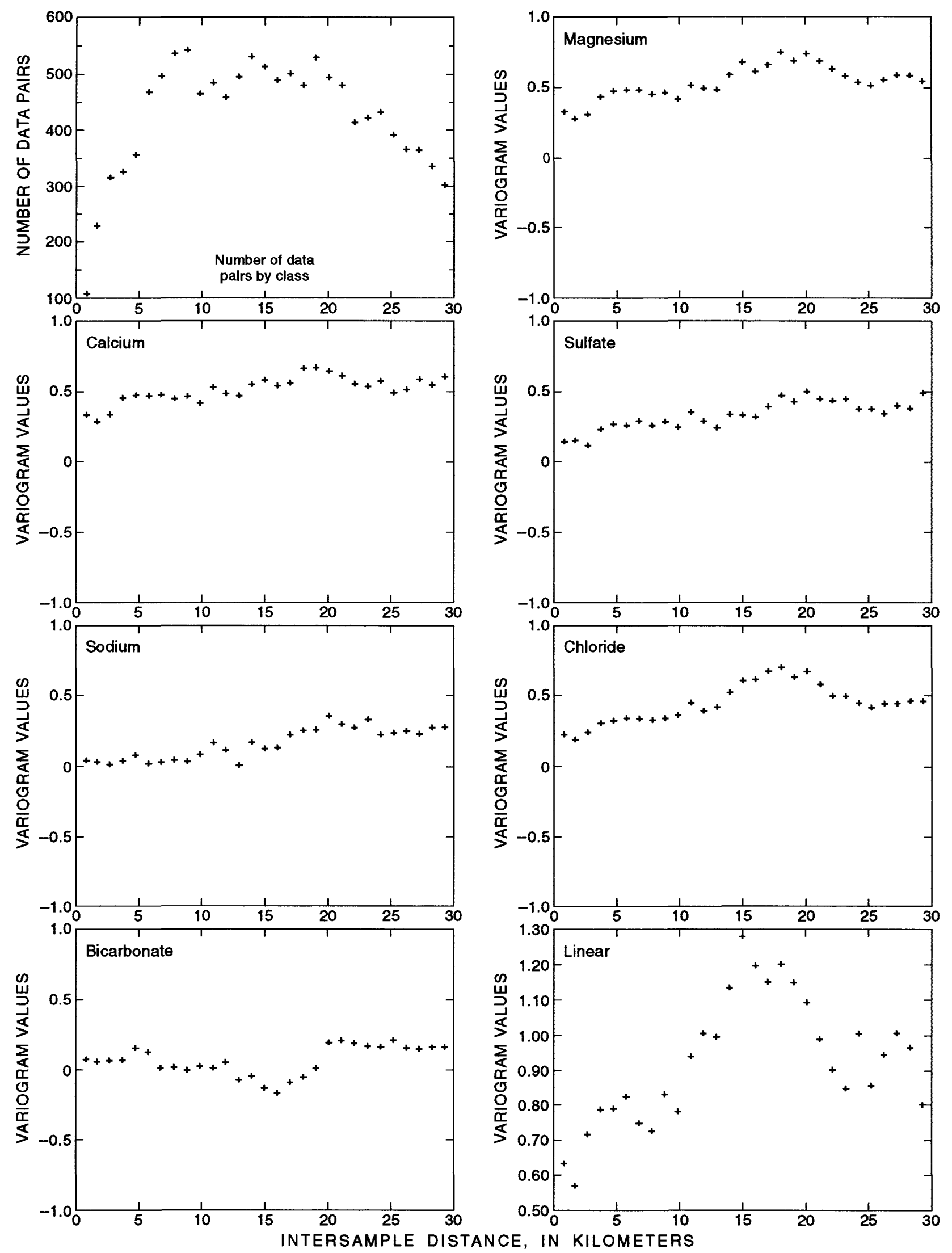

Figure 6. Data-pair distribution and cross variograms, 1975-77. 

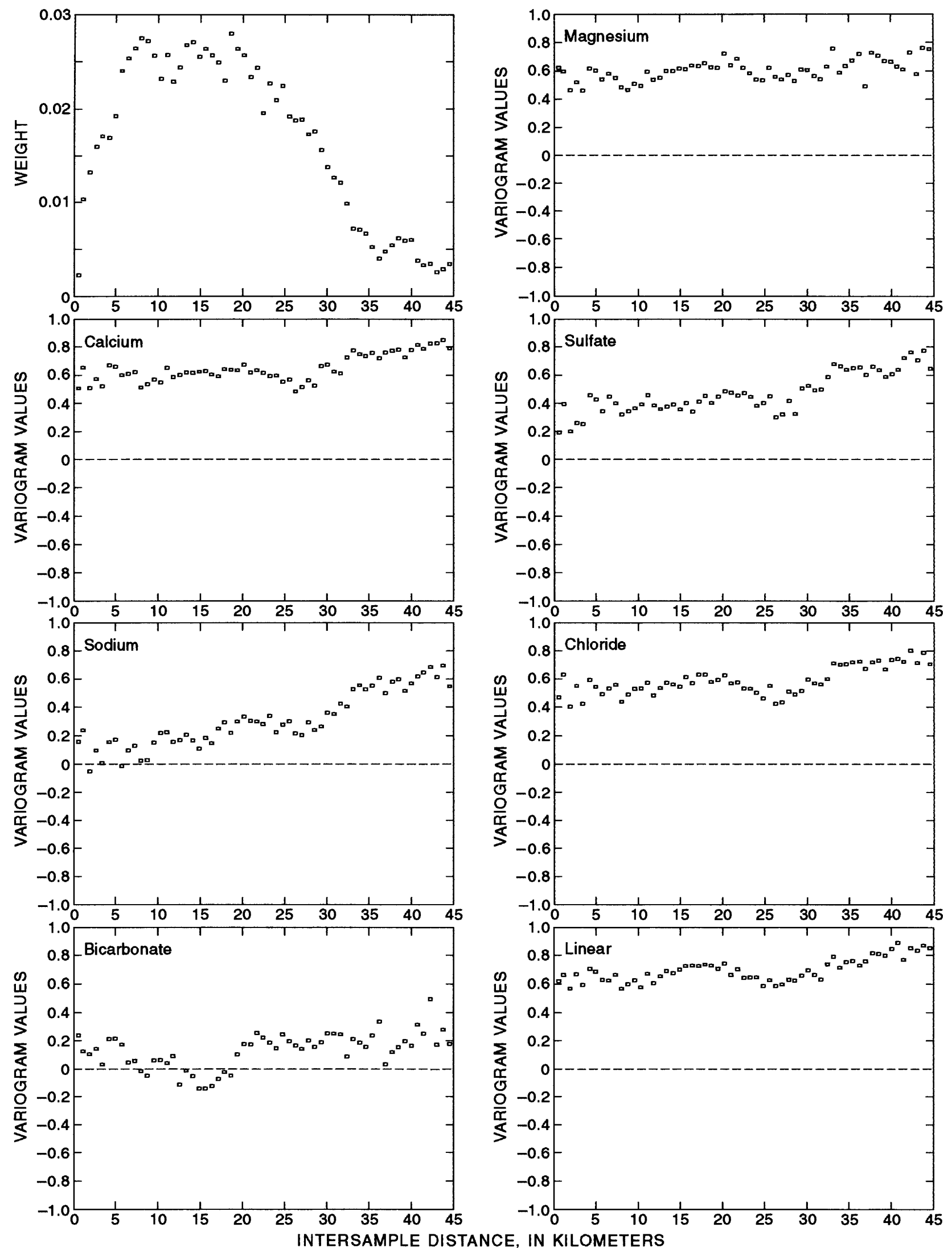

Figure 7. Scaled cross variograms, 1975-77. 
the three time periods (fig. 8). The variogram for 1980-85 differs markedly from variograms for 1975-77 and 1986-90. As previously discussed, the variograms were modeled with a least-squares technique using an error function described by Cressie (1985). The sample variograms for 1975-77, 1980-85, and 1986-90 were best fit with spherical, linear, and exponential models, respectively. For data sets from 1975-77 and 1986-90, selection of a model type is tenuous because the variogram values for each period reach a maximum at about 18 and $28 \mathrm{~km}$, respectively, and then generally decrease with increasing distance. The spherical variogram for 1975-77 had a sill value of between 1.0 and $1.1 \mathrm{mg}^{2} / \mathrm{L}^{2}$ and a range of about $17 \mathrm{~km}$. The 1980-85 linear model was characterized by the lack of a sill. Theoretically, an exponential model approaches a sill asymptotically, but in the case of the exponential model for the 1986-90 set, the variogram did not approach an asymptote by a lag of $30 \mathrm{~km}$.

All three variograms had significant nuggets in that the variogram values failed to approach the origin at a distance of 0 . The nugget values for each variogram ranged from 0.3 to $0.4 \mathrm{mg}^{2} / \mathrm{L}^{2}$. A significant nugget effect reflects either uncertainty in the data, the need to sample at smaller intervals, or mixing of water from different intervals in a single well. The complexities of the variograms also could be the result of combining data from a 3- to 5-year period into a single data set and using an isotropic model.

On the basis of variogram analysis and the results of later cross validation, manganese cokriged best with nitrate for 1975-77 and 1986-90, and calcium cokriged best with nitrate in 1980-85. The associated sample and modeled cross variograms for 1975-77, 1980-85, and

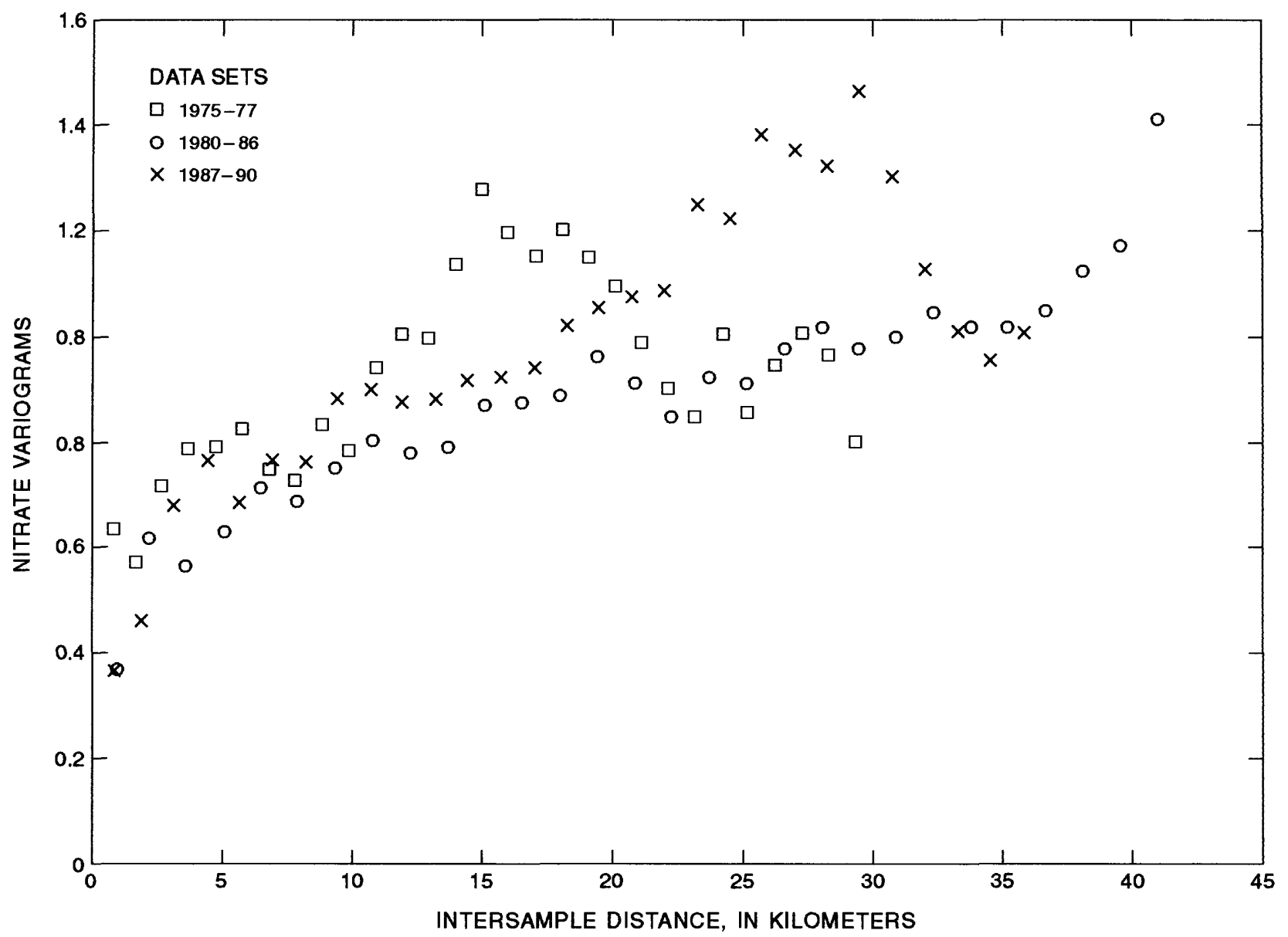

Figure 8. Comparison of variograms. 

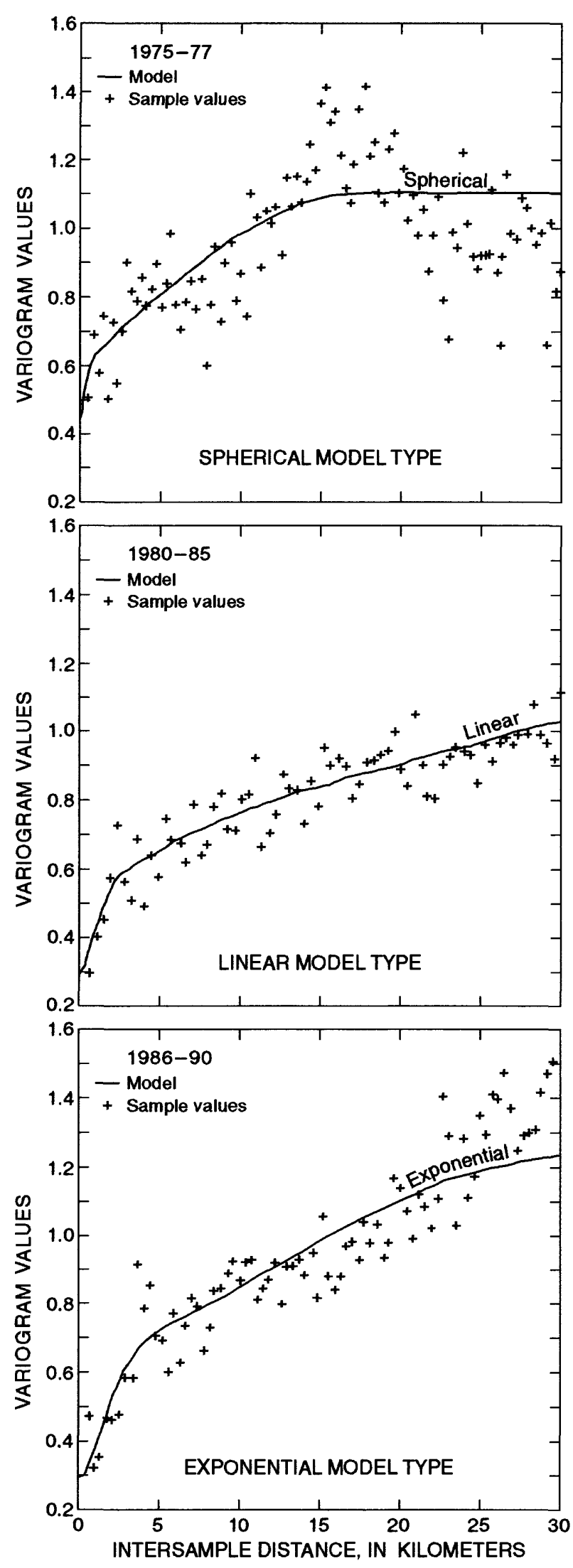

Figure 9. Sample variograms and models.
1986-90 (fig. 10) were best fit with spherical, linear, and exponential models, respectively, as was the case for the kriging variograms (fig. 9). The models for each variogram and cross variogram for a given time period were the same probably because nitrate did not correlate well with either of the chosen variables.

\section{Comparison of Interpolation Methods}

Maps of nitrate distribution were drawn using inverse-distance squared weighting, radial-basis function, kriging, and cokriging on the three data sets. Comparisons between data sets using the same technique were done in order to gain an understanding of how ground-water chemistry, specifically nitrate distribution, has changed over the last 15 years. Such comparisons are similar to a crude time-series analysis of the problem. The variables selected for use in the interpolation procedures include bicarbonate, calcium, magnesium, chloride, sodium, sulfate, and depth to water.

Each of the four methods is an exact interpolator - that is each will reproduce a data value if used at a data location. The last two methods use the data in the choice of the model parameters, which is important because the data are allowed to indicate the type of spatial correlation they exhibit rather than relying on arbitrary assumptions.

The reliability or quality of the map produced by the four methods was assessed using a procedure called cross validation. In cross validation, a data value is removed from the data set, an estimate is made at that site, and the two values are compared to give measures of goodness-of-fit. Simply stated, the method estimates the missing data point from the remaining data. This analysis also indicates the degree of uncertainty associated with estimates of nitrate concentration at points some distance from known data points.

Good cross-validation results are characterized by the following items.

1. Estimates that have statistics similar to those of the actual values. 

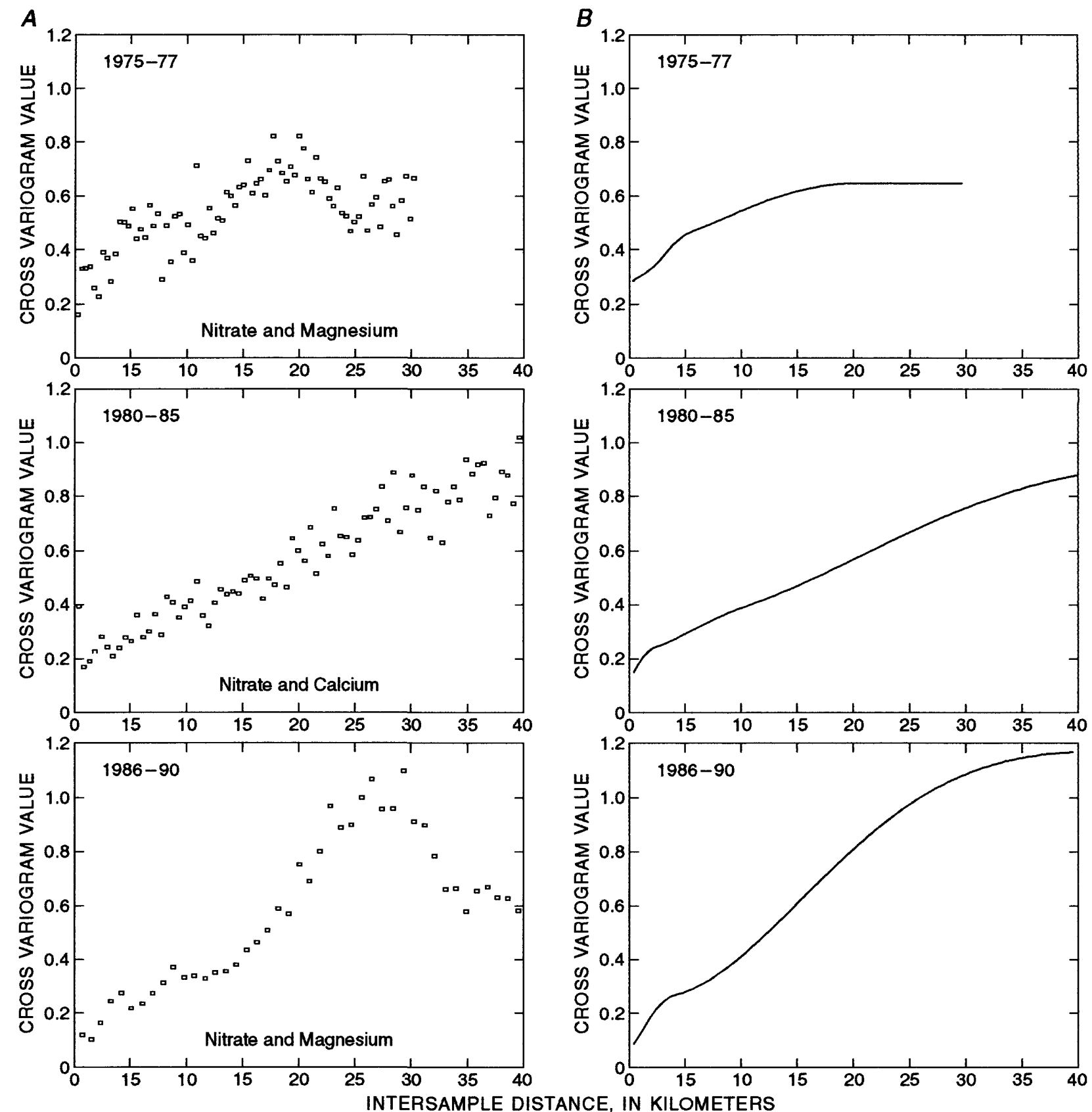

Figure 10. Sample values and model cross variograms. $A$, Sample values. $B$, Model cross variograms.

2. Differences between the actual and estimated values that have means of zero.

3. Small absolute differences between the actual and estimated values and a lack of extreme values.

4. A unit variable given by the estimate minus the true value that when divided by the estimation standard deviation is standard normally distributed (ideally a mean of zero, unit variance, zero skewness, and kurtosis of three).

Kriging, cokriging, and radial-basis function generally produced good results from all three data sets. As expected, cokriging minimized the estimation variance; however, this did not necessarily result in the best characteristics for the other cross-validation statistics. The best method 
was determined by considering all of the above characteristics giving slightly more weight to the mean-squared difference and the correlation with the true value. In addition to indicating which method was most reliable, cross validation also indicated that the relation between particular pairs used in the cokriging process was not consistent from one data set to another. In several instances, pairs of variables that had poor results in one data set had good results in another. Nitrate and magnesium gave the best cokriging results for 1975-77 and 1986-90, and nitrate and calcium gave the best results for $1980-85$. In contrast, nitrate and magnesium in 1980-85, and nitrate and calcium in 1975-77 did poorly in cross validation.

From an analysis of the cross-validation results, cokriging maps resulted in the best estimates, and they were accepted as being the most reliable (table 2). Kriging consistently did almost as well as any of the cokriging results (tables 3-5). Because of the difficulties inherent in the cokriging process, kriging, although not optimal, was the fastest way to obtain reasonably good results. Whether the savings in time is worth the slight decrease in accuracy is a subjective decision that would depend on the needs of a particular mapping project.

The variation in results from one data set to another may reflect physicochemical processes, such as recharge of dilute water along major drainages. For example, data for 1980-85 likely reflect to some degree the effects of large recharge events that occurred in 1978, 1980, and 1983. Alternatively, at least part of the variation may be related to the distribution of data points in each set. Data for 1975-77 and 1986-90 includes mainly data obtained from irrigation companies and other water-service organizations. The data for 1980-85 include mainly samples taken by the USGS in 1980, 1984, and 1985; and samples taken by ADWR in 1983. This data set provided a uniform coverage of the study area compared with the clustered sample distribution associated with the earlier and later periods. In Buckeye Valley, for example, sample points for 1980-85 generally are scattered; whereas, sample points for 1975-77 and 1986-90 are from irrigation-company wells that generally occur in a linear fashion along Roosevelt and Buckeye Canals. Follow-up studies could explore the effect of data distribution on variability of results by building a data base for 1980-85 using non-USGS and (or) ADWR data.

The variables that correlated best with nitrate on the basis of traditional bivariate statistics were not necessarily the best on the basis of cross validation. On the basis of bivariate statistical analysis, nitrate correlated best with calcium for 1975-77 and with magnesium for 1980-85 and 1986-90 (tables 3-5). Cross-validation results, however, indicate that nitrate cokriged best with magnesium for 1975-77 and 1986-90 and with calcium for 1980-85. The associated crossvariogram variables that correlate well with nitrate generally varied smoothly and showed extremely

Table 2. Ranking of the top four statistical mapping methods, $1975-77,1980-85$, and 1986-90

[Dashes indicate method was not ranked in the top four]

\begin{tabular}{|c|c|c|c|c|c|c|c|}
\hline \multirow[b]{2}{*}{ Method } & \multicolumn{3}{|c|}{ Data sets } & \multirow[b]{2}{*}{ Method } & \multicolumn{3}{|c|}{ Data sets } \\
\hline & $1975-77$ & $1980-85$ & $1986-90$ & & $1975-77$ & $1980-85$ & $1986-90$ \\
\hline Nitrate (true) …....................... & $\overline{---}$ & --- & -- & Kriging (nitrate alone) ... & $\ldots$ & 4 & - \\
\hline Cokriging: & & & & Radial-basis function & & & \\
\hline Nitrate and calcium .......... & --- & 1 & 3 & multiquadric .................. & --- & --- & -- \\
\hline Nitrate and chloride ......... & 3 & 2 & --- & $\begin{array}{l}\text { Inverse-distance squared } \\
\text { weighting: }\end{array}$ & & & \\
\hline Nitrate and magnesium ... & 1 & --- & 1 & 20 or 10 neighbors ...... & --- & --- & -- \\
\hline $\begin{array}{l}\text { Nitrate and principal- } \\
\text { component variable } . . . . . .\end{array}$ & 4 & 3 & 4 & 4 neighbors ...................... & --- & --- & -- \\
\hline $\begin{array}{l}\text { Nitrate and linear- } \\
\text { regression variable ......... }\end{array}$ & 2 & --- & 2 & Universal.......................... & --- & -- & -- \\
\hline
\end{tabular}


Table 3. Summary statistics for each statistical method, 1975-77

\begin{tabular}{|c|c|c|c|c|c|c|c|}
\hline Method & $\begin{array}{c}\text { Mean } \\
\text { difference }\end{array}$ & $\begin{array}{c}\text { Mean } \\
\text { difference } \\
\text { squared }\end{array}$ & $\begin{array}{c}\text { Correlated } \\
\text { with true } \\
\text { value }\end{array}$ & Variance & Mean & Minimum & Maximum \\
\hline 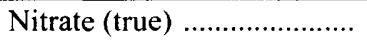 & 0.00 & 0.00 & 1.00 & 0.98 & 10.03 & 7.25 & 11.83 \\
\hline \multicolumn{8}{|l|}{ Cokriging: } \\
\hline Nitrate and calcium .............. & -.22 & 24.75 & .16 & 5.05 & 10.26 & -.02 & 39.78 \\
\hline Nitrate and chloride .............. & .01 & .44 & .73 & .70 & 10.02 & 8.18 & 11.72 \\
\hline Nitrate and magnesium ....... & .01 & .43 & .74 & .72 & 10.02 & 7.89 & 11.92 \\
\hline $\begin{array}{l}\text { Nitrate and principal- } \\
\text { component variable } \ldots . . . .\end{array}$ & .01 & .55 & .66 & .61 & 10.03 & 8.84 & 11.69 \\
\hline $\begin{array}{l}\text { Nitrate and linear- } \\
\quad \text { regression variable ......... }\end{array}$ & .03 & .39 & .80 & .98 & 10.00 & 7.34 & 12.05 \\
\hline Kriging (nitrate alone) ........ & .01 & .62 & .59 & .59 & 10.02 & 8.70 & 11.76 \\
\hline $\begin{array}{l}\text { Radial-basis function } \\
\text { multiquadric }\end{array}$ & \multirow[t]{2}{*}{.03} & \multirow[t]{2}{*}{.77} & \multirow[t]{2}{*}{.54} & \multirow[t]{2}{*}{.83} & \multirow[t]{2}{*}{10.00} & \multirow[t]{2}{*}{7.70} & \multirow[t]{2}{*}{11.97} \\
\hline $\begin{array}{l}\text { Inverse-distance squared } \\
\text { weighting: }\end{array}$ & & & & & & & \\
\hline 20 neighbors ............................. & .04 & .65 & .58 & .71 & 9.99 & 8.07 & 11.39 \\
\hline 4 neighbors ............................ & .08 & .82 & .53 & .88 & 9.96 & 7.45 & 11.64 \\
\hline
\end{tabular}

Table 4. Summary statistics for each statistical method, $1980-85$

\begin{tabular}{|c|c|c|c|c|c|c|c|}
\hline Method & $\begin{array}{c}\text { Mean } \\
\text { difference }\end{array}$ & $\begin{array}{c}\text { Mean } \\
\text { difference } \\
\text { squared }\end{array}$ & $\begin{array}{c}\text { Correlated } \\
\text { with true } \\
\text { value }\end{array}$ & Variance & Mean & Minimum & Maximum \\
\hline Nitrate (true) & 0.00 & 0.00 & 1.00 & 1.00 & 10.00 & 5.40 & 11.61 \\
\hline \multicolumn{8}{|l|}{ Cokriging: } \\
\hline Nitrate and calcium.......... & .00 & .33 & .82 & .83 & 10.00 & 6.18 & 11.39 \\
\hline Nitrate and chloride & .01 & .38 & .79 & .82 & 9.99 & 6.04 & 11.29 \\
\hline Nitrate and magnesium .. & .42 & 14.54 & .42 & 4.11 & 9.58 & -26.27 & 28.78 \\
\hline $\begin{array}{l}\text { Nitrate and principal- } \\
\text { component variable }\end{array}$ & .00 & .42 & .76 & .70 & 10.00 & 5.84 & 11.15 \\
\hline $\begin{array}{l}\text { Nitrate and linear- } \\
\text { regression variable } \ldots . . . . .\end{array}$ & .01 & 1.02 & .50 & 1.02 & 9.99 & 5.26 & 12.53 \\
\hline Kriging (nitrate alone) ........ & .00 & .52 & .69 & .69 & 10.00 & 5.66 & 10.99 \\
\hline $\begin{array}{l}\text { Radial-basis function } \\
\text { multiquadric }\end{array}$ & .01 & .59 & .66 & .82 & 9.99 & 6.64 & 11.54 \\
\hline \multicolumn{8}{|l|}{$\begin{array}{l}\text { Inverse-distance squared } \\
\text { weighting: }\end{array}$} \\
\hline 20 neighbors ............................ & -.02 & .58 & .65 & .71 & 10.02 & 7.43 & 11.27 \\
\hline 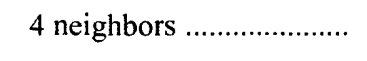 & -.01 & .64 & .63 & .81 & 10.01 & 7.28 & 11.44 \\
\hline Universal & -.06 & .65 & .61 & .47 & 10.06 & 8.76 & 11.01 \\
\hline
\end{tabular}


Table 5. Summary statistics for each statistical method, 1986-90

\begin{tabular}{|c|c|c|c|c|c|c|c|}
\hline Method & $\begin{array}{c}\text { Mean } \\
\text { difference }\end{array}$ & $\begin{array}{c}\text { Mean } \\
\text { difference } \\
\text { squared }\end{array}$ & $\begin{array}{l}\text { Correlated } \\
\text { with true } \\
\text { value }\end{array}$ & Variance & Mean & Minimum & Maximum \\
\hline Nitrate (true) & 0.00 & 0.00 & 1.00 & 1.00 & 9.99 & 7.34 & 11.84 \\
\hline \multicolumn{8}{|l|}{ Cokriging: } \\
\hline Nitrate and calcium & .00 & .46 & .74 & .79 & 10.00 & 8.06 & 11.25 \\
\hline Nitrate and chloride ..................... & -.75 & 110.22 & .02 & 1.69 & 1.01 & 1.96 & 19.48 \\
\hline Nitrate and magnesium ............... & .00 & .43 & .76 & .82 & 9.99 & 7.05 & 11.27 \\
\hline $\begin{array}{l}\text { Nitrate and principal- } \\
\text { component variable }\end{array}$ & .00 & .47 & .73 & .72 & 9.99 & 8.10 & 11.12 \\
\hline $\begin{array}{l}\text { Nitrate and linear- } \\
\text { regression variable .................... }\end{array}$ & .00 & .43 & .76 & .78 & 10.00 & 7.93 & 11.34 \\
\hline Kriging (nitrate alone) & .00 & .52 & .69 & .72 & 9.99 & 7.98 & 11.09 \\
\hline 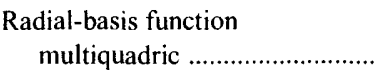 & .00 & .56 & .68 & .84 & 9.99 & 7.55 & 11.52 \\
\hline \multicolumn{8}{|l|}{$\begin{array}{l}\text { Inverse-distance squared } \\
\text { weighting: }\end{array}$} \\
\hline 20 neighbors ............................. & .00 & .56 & .67 & .76 & 9.99 & 8.08 & 11.28 \\
\hline 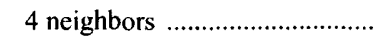 & .00 & .60 & .66 & .85 & 10.00 & 7.59 & 11.59 \\
\hline
\end{tabular}

good correlation at the first lags. Other variables, including sodium, sulfate, and chloride, correlated as well or nearly as well in each case. Each offered varying degrees of improvement (or degradation) from the kriging results. The best way to determine which variables correlated best with nitrate was to examine the scaled cross-variogram plots (fig. 7).

The results of this analysis also demonstrated the uncertainty related to the cokriging procedure. Cokriging and radial-basis function may lead to large linear systems of equations for the weights, which may cause problems resulting from ill-conditioned matrices. This problem has not been dealt with in sufficient detail in the statistical literature. Another problem with the method is that it requires variogram and cross-variogram modeling assumptions that are not determined by actual data; therefore only someone already versed in the basics of the technique can use it effectively. Perhaps the most important of these assumptions is that the Cauchy-Schwarz condition for matrix invariability is satisfied. If this condition is not satisfied, inaccurate values could be produced. Common sense, experience, comparison with other physical and chemical data that constrain the regional distribution, and cross validation are necessary to evaluate the complete uncertainty and reasonableness of any regional statistical estimate.
Contour maps generated from the regional estimates of each method (fig. 11) were visually distinct and varied in degree of complexity. The radial-basis function, cokriging, and kriging maps are characterized by northeast- to southwesttrending oval contours; whereas, the inversedistance map is more irregular. The different overall contour patterns on each map demonstrate how the choice of interpolation can have a significant effect on the simulated distribution of nitrate. The concentric contours seem less prevalent in the radial-basis function map and are more common on the other three maps. The contour map for the inverse-distance squared weighting appeared to be the simplest, the radialbasis function map was complex, and the kriging and cokriging maps appear more complex. The visual appearance of a particular map is not of primary importance; the relevance of map values to actual data values in the field is more critical.

The cokriging maps that were determined to be most reliable are characterized by steep gradients near some points on the map and would be considered by some to be visually displeasing. As mentioned earlier, cokriging is an exact interpolator, but does not necessarily produce a continuous estimation surface. The steep gradients are a function of the variogram model. The 

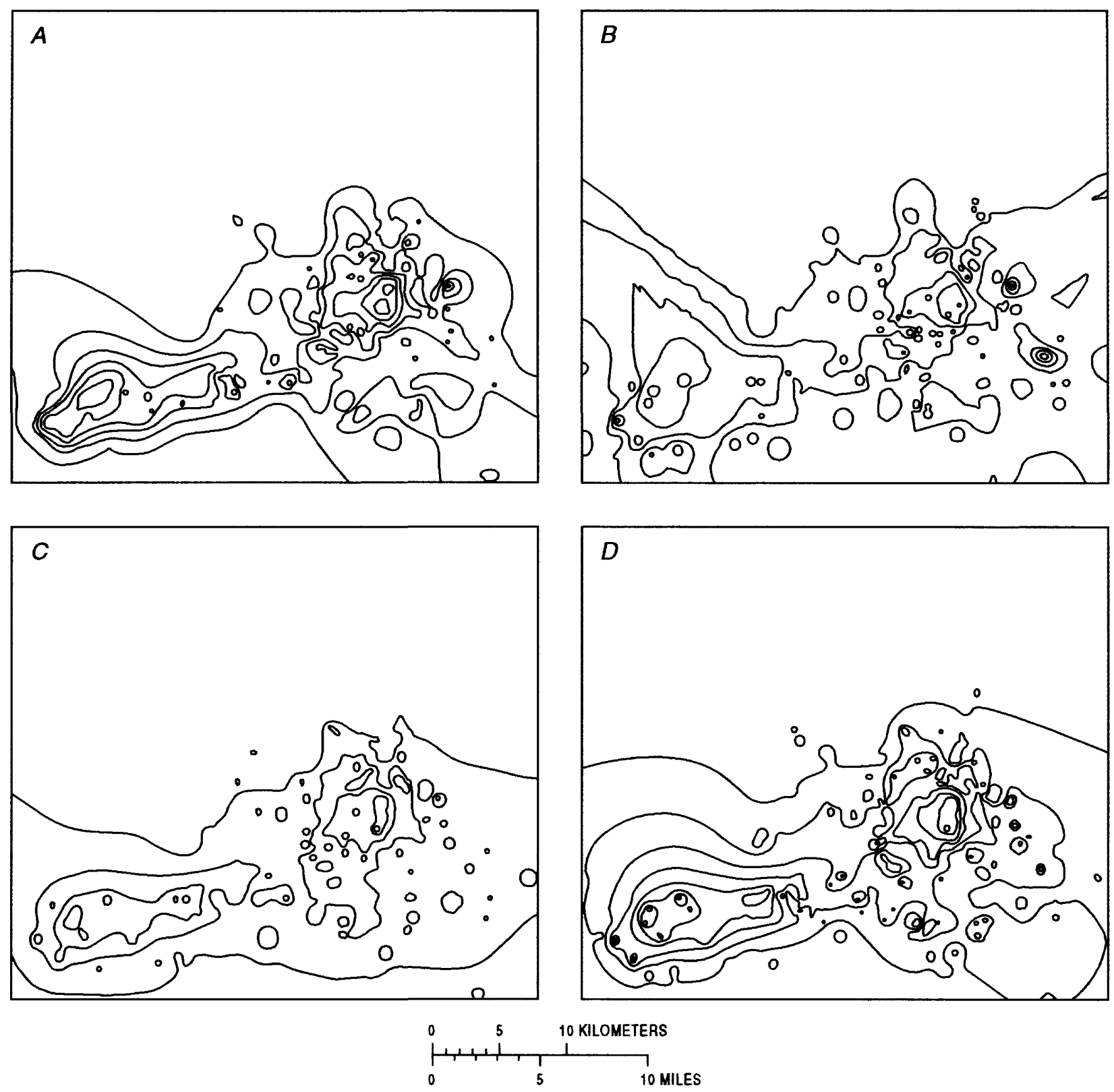

Figure 11. Contours of nitrate created by $(A)$ radial-basis function, $(B)$ inverse-distance squared weighting, $(C)$ cokriging, and $(D)$ kriging.

variograms for each data set indicate that nitrate covaries significantly within only a few kilometers. When locations for estimates are far from points with measured values, the estimates will be given by the drift surface. Significant departure from the drift surface will occur only as a location for an estimate approaches a data point, in which case, the estimate will be the same as the actual value at that point. The difference between the estimate at a data point and at an adjacent point is related to the size of the nugget (figs. 10-11).

\section{Cokriged Distribution Of Nitrate In Ground Water}

The cokriged distribution of nitrate concentrations in ground water for 1975-77, 1980-85, and 1986-90 generally can reveal how nitrate concentrations changed through time (figs. 12-14). The cokriged contour maps were contoured using the Geographical Resources Analysis Support System (GRASS). This public domain geographic- 


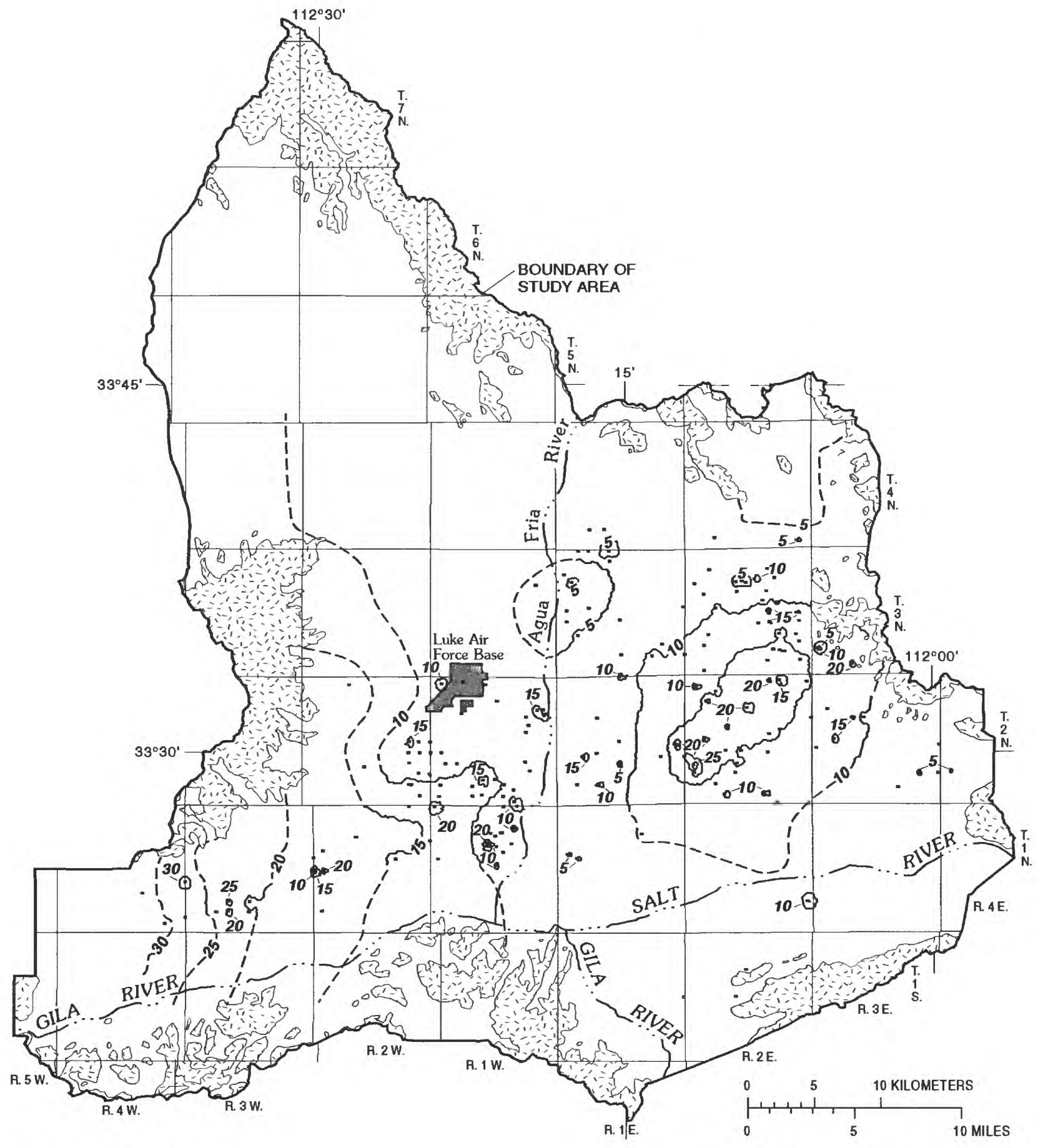

Base from U.S. Geological Survey State base map, 1:1,000,000, 1974

\section{EXPLANATION}

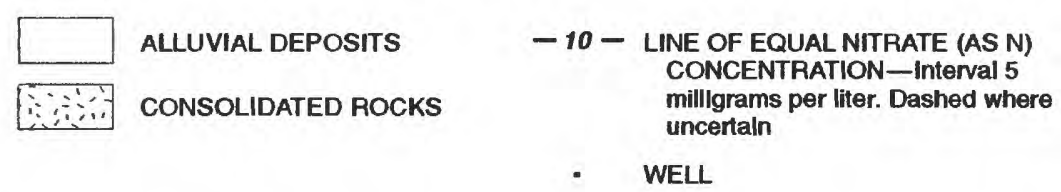

Figure 12. Adjusted cokriged distribution of nitrate in ground water, 1975-77. 


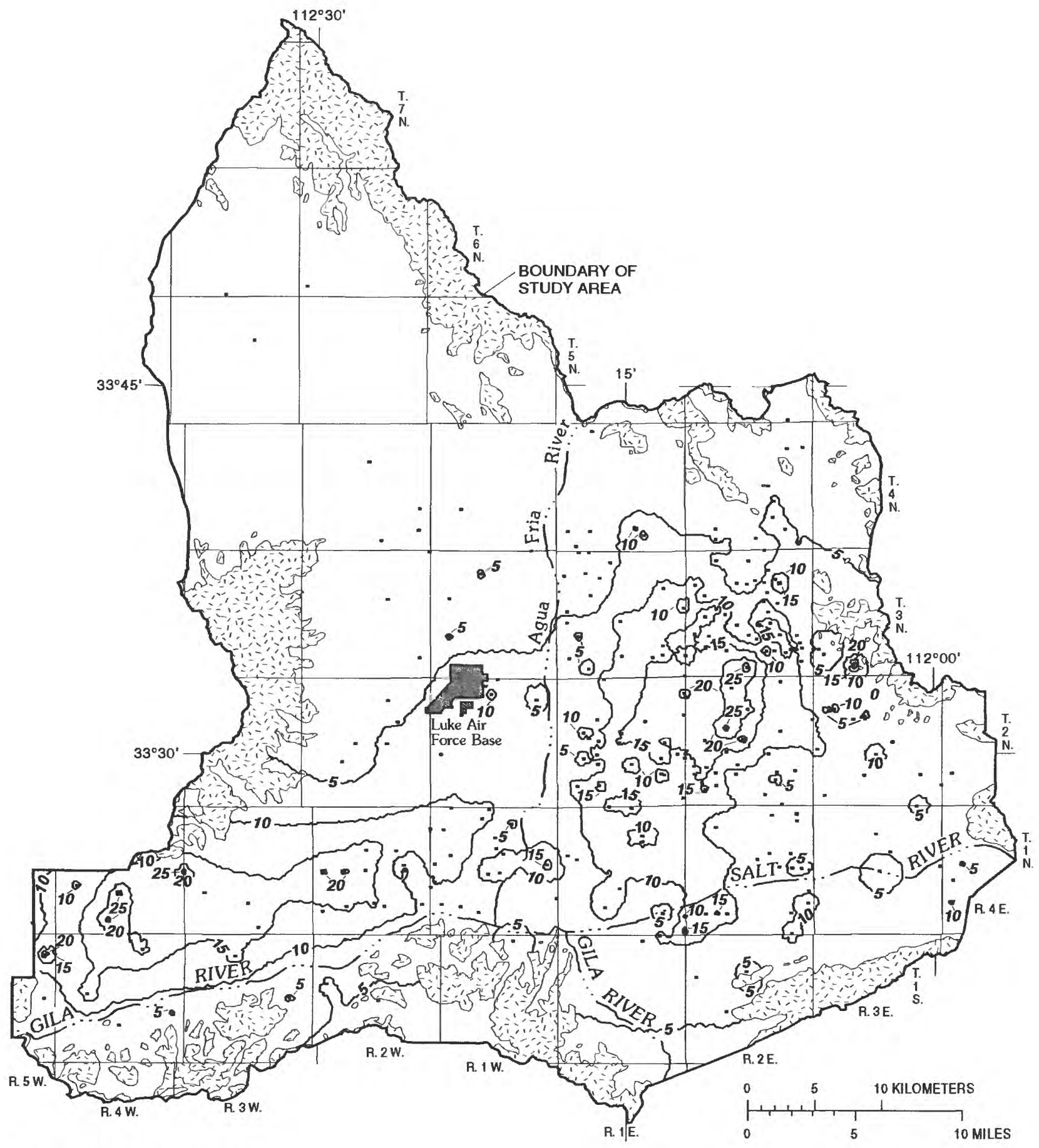

Base from U.S. Geological Survey State base map, 1:1,000,000, 1974

EXPLANATION

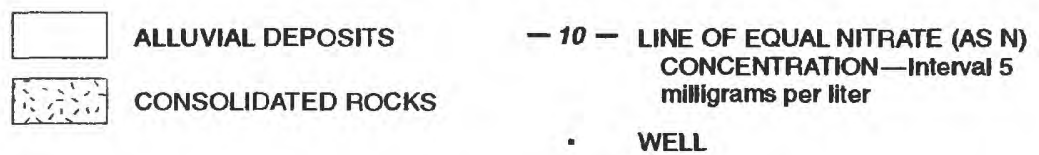

Figure 13. Adjusted cokriged distribution of nitrate in ground water, 1980-85. 


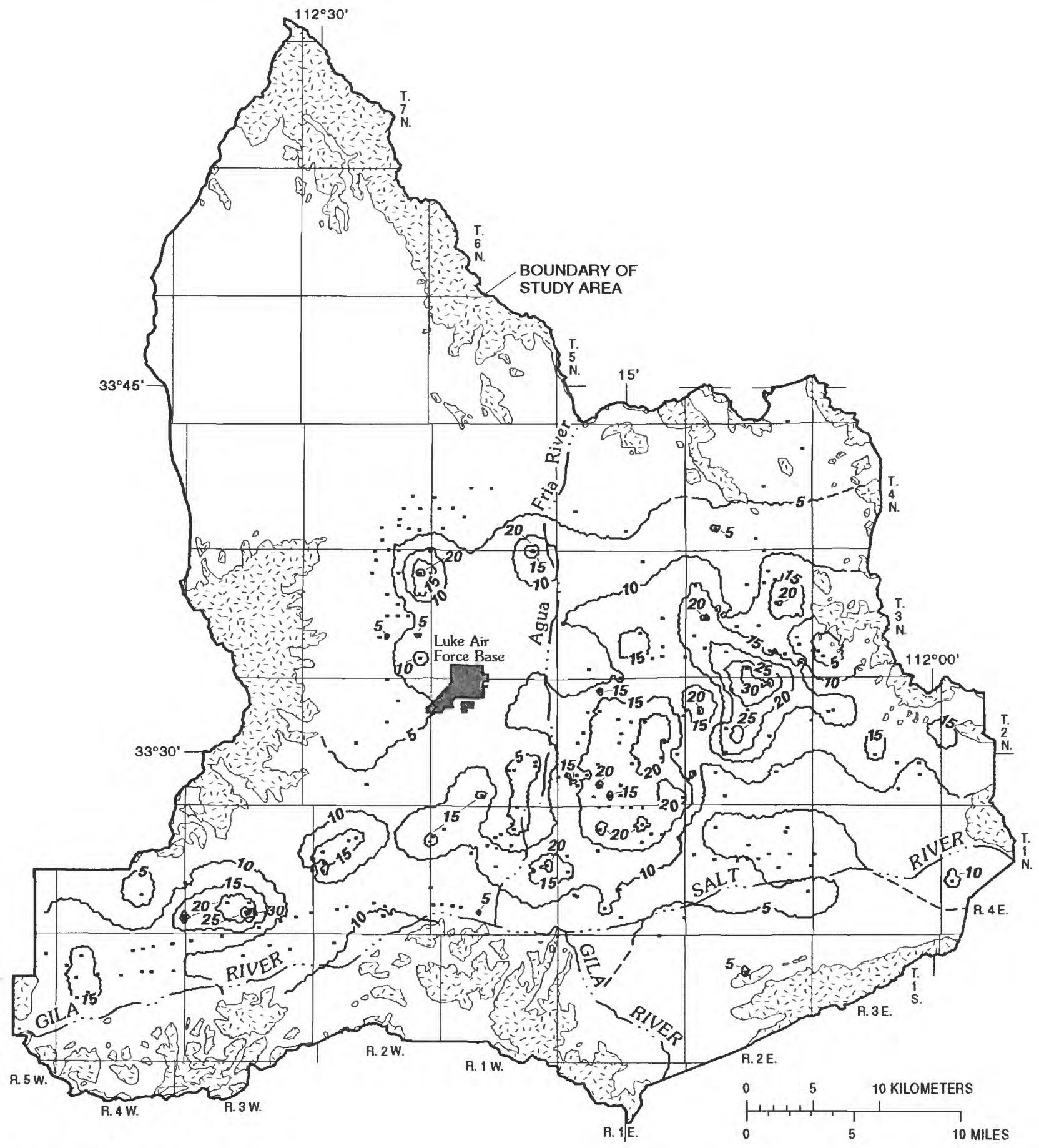

Base from U.S. Geological Survey State base map, 1:1,000,000, 1974

\section{EXPLANATION}

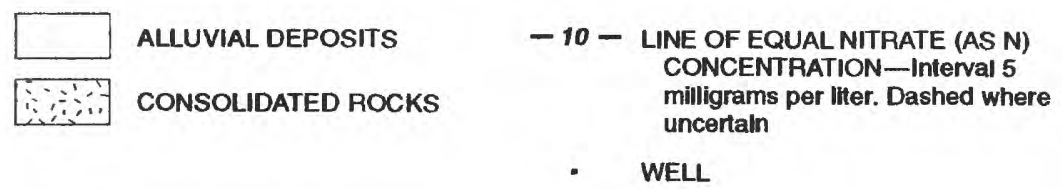

Figure 14. Adjusted cokriged distribution of nitrate in ground water, 1986-90. 
information system was developed by the U.S. Army Construction Engineering Research Laboratory, and is supported by the USGS and other agencies. Grid files of cokriged estimates were combined with the original data points. In most areas, the changes in cokriged distribution from one time period to another are the result of hydrologic and geochemical processes. In other areas, the changes may reflect differences in data distribution from one time period to another and not actual changes in nitrate concentrations through time.

In Buckeye Valley, contours of equal nitrate concentration for 1975-77 trend roughly north to south and extend to the north and south margins. This trend reflects, in part, the linear northeastsouthwest trend of available nitrate data (fig. 12). Data for this time period were mostly from an irrigation company, many of whose wells were along a canal that runs east to west. No data were available for the margins of the basin where the later maps indicate that nitrate values generally are lower than along the central part of the valley. The contours for data for 1975-77 probably do not reflect the actual distribution of nitrate along the margins of Buckeye Valley. In contrast to the nitrate data for 1975-77, the nitrate data for 1980-85 (fig. 13) are more evenly and widely distributed, and the resulting cokriged contours better reflect the general distribution of nitrate. The contrast in general appearance between the two sets of contours illustrates one of the limitations of computer-generated contours. The cokriged distribution of nitrate in Buckeye Valley for $1986-90$ (fig. 14) is similar to that of 1980-85; however, the areas in which nitrate concentrations exceeded $10 \mathrm{mg} / \mathrm{L}$ are not similar. In $\mathrm{T} .1 \mathrm{~S}$., R. $3 \mathrm{~W}$., the area in which kriged nitrate concentrations exceeded $10 \mathrm{mg} / \mathrm{L}$ in $1986-90$ extends to bedrock south of the Gila River mainly because of the lack of data south of the river for this time period. If the previous contour distribution, ground-water flow directions, and bedrock configuration had been taken into account, it is unlikely that the 10-milligram-per-liter contour for this area would have been drawn into the bedrock. As with any computer-generated data, the cokriged nitrate contours should be checked for consistency against all other available hydrologic data and modified when necessary.
Cokriged nitrate concentrations for 1980-85 exceeded $20 \mathrm{mg} / \mathrm{L}$ in a 12 -square-kilometer area in Phoenix and Glendale and exceeded $10 \mathrm{mg} / \mathrm{L}$ in a 280-square-kilometer area that extended to the Salt River in the southwest quarter of T. 1 N., R. 2 E. For 1986-90, cokriged nitrate concentrations were less than $10 \mathrm{mg} / \mathrm{L}$ along the entire reach of the Salt River in west Salt River Valley and probably were the result of recharge of runoff from the Salt and Gila Rivers in 1978, 1980, and 1983 during higher-than-normal precipitation. Apparently although the latter two periods of recharge occurred during 1980-85, they did not have an immediate effect on nitrate concentrations throughout much of the area along the Salt and Gila Rivers. Farther north in Phoenix and Glendale, the area in which nitrate concentrations exceeded $10 \mathrm{mg} / \mathrm{L}$ expanded to $490 \mathrm{~km}^{2}$ for 1986-90. In Buckeye Valley, nitrate concentrations exceeded $10 \mathrm{mg} / \mathrm{L}$ in an area of $300 \mathrm{~km}^{2}$ for 1980-85 and $220 \mathrm{~km}^{2}$ for $1986-90$. The measured decrease is likely the result of recharge from the Gila River in the early 1980's but possibly could be an artifact of the different data distributions associated with each data set. In the Phoenix area, cokriged nitrate concentrations for 1975-77 exceeded $10 \mathrm{mg} / \mathrm{L}$ in an area of about $290 \mathrm{~km}^{2}$ and exceeded $20 \mathrm{mg} / \mathrm{L}$ in an area of $1.4 \mathrm{~km}^{2}$.

The cokriged variances are one measure of the reliability of the cokriged nitrate concentration at a given location (figs. 15-17). Because the variances are for the transformed data, they have no direct relation to actual nitrate values. Cokriged variance, however, can be used to examine the relative reliability within a single map or by comparing maps. On the basis of an examination of the cokriged contours and distribution of data points for each data set, water-level contours, and basin configuration, the cokriged nitrate concentrations in areas in which the cokriged variance exceeded 0.8 were designated "uncertain" and are indicated as such by dashed contours (figs. 12-14).

Cokriged variances were less than 0.8 in the Phoenix-Glendale area and south of LAFB in part because of the high density of available data in these areas compared with other areas. Cokriged variances were greater than 0.8 along the margins of the basin and northeast of LAFB. 


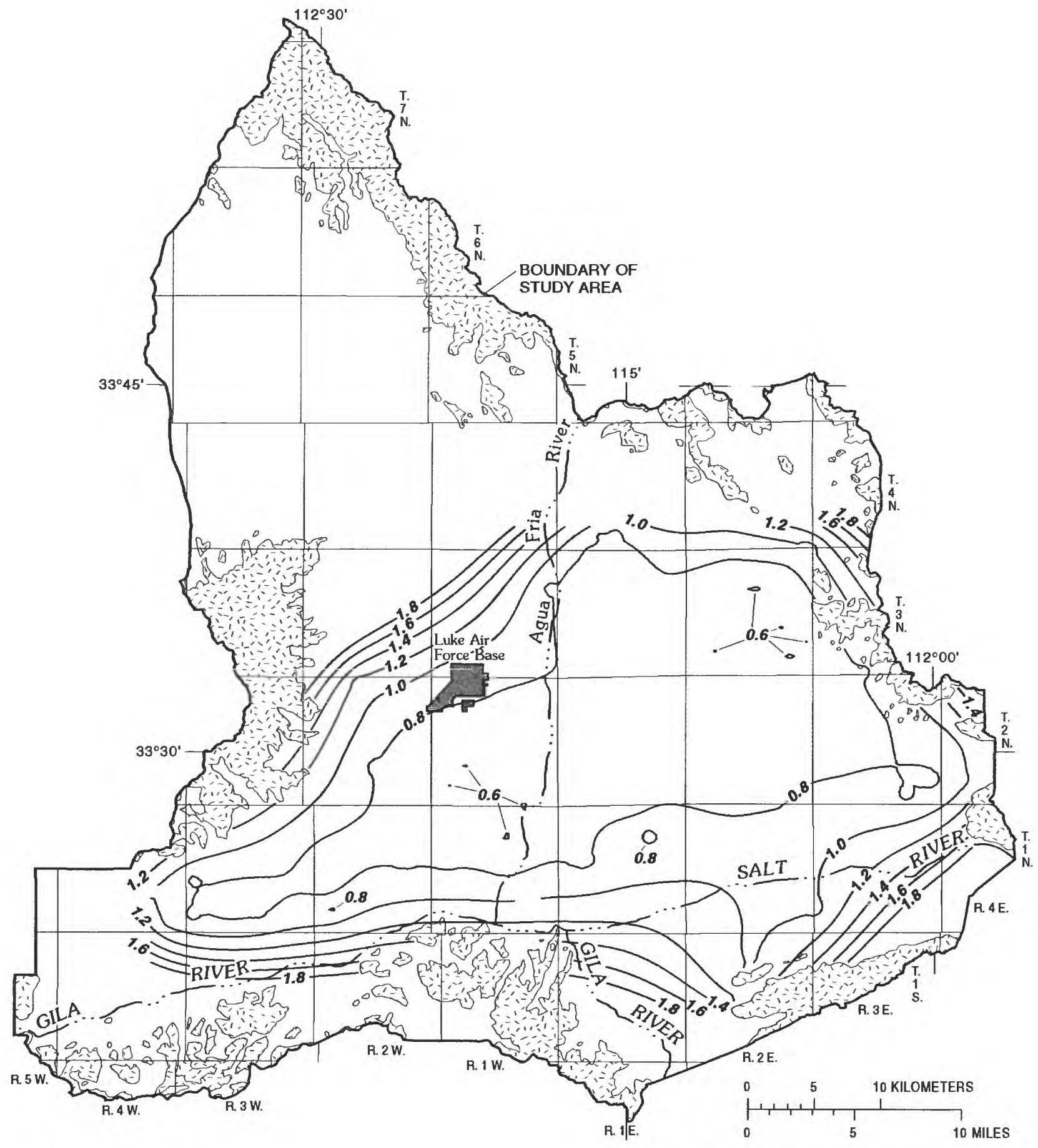

Base from U.S. Geological Survey State base map, 1:1,000,000, 1974

EXPLANATION 


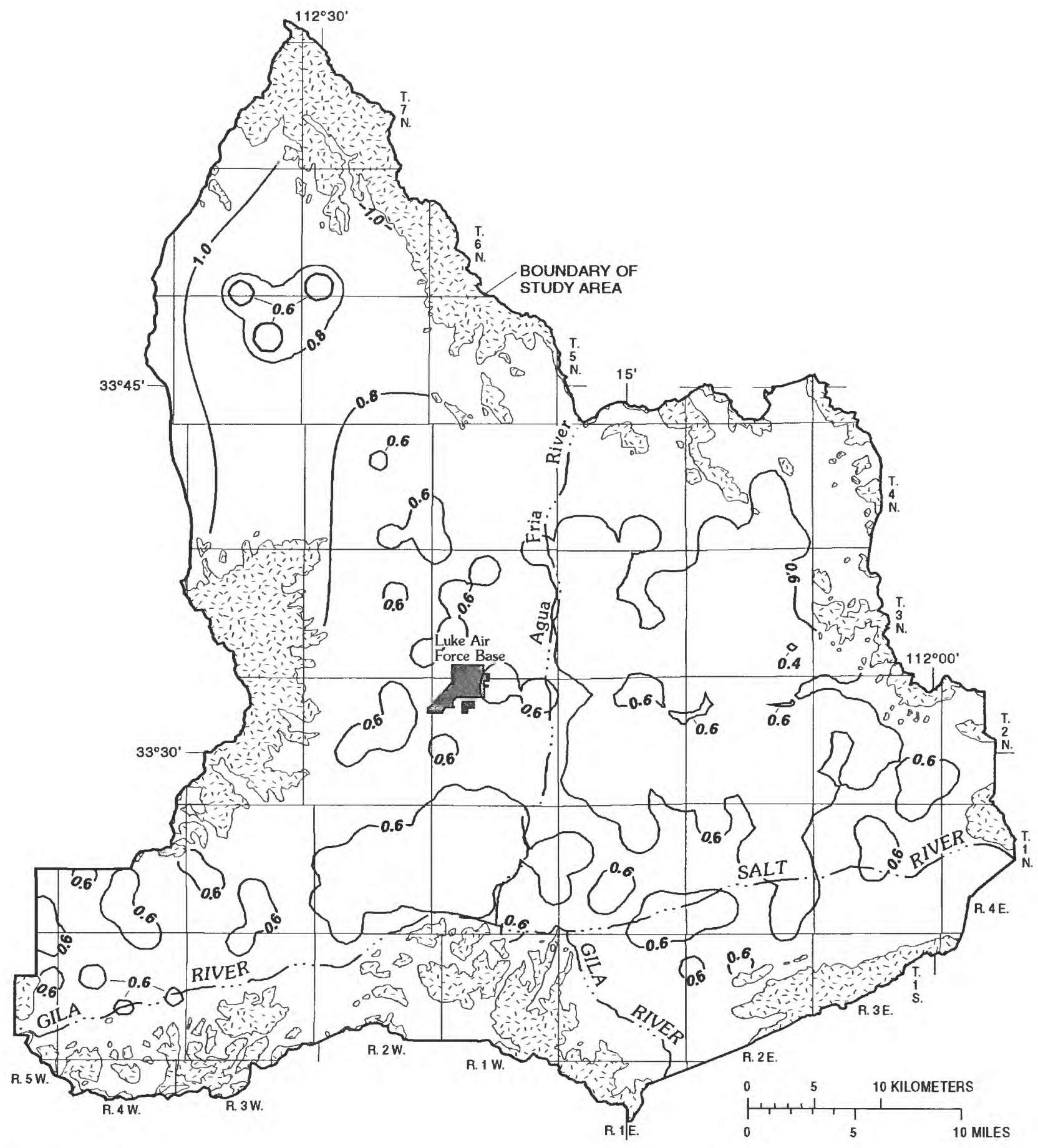

Base from U.S. Geological Survey State base map, 1:1,000,000, 1974

EXPLANATION

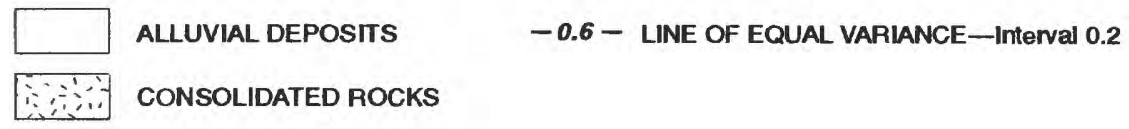

Figure 16. Cokriged variance of nitrate distribution in ground water, 1980-85. 


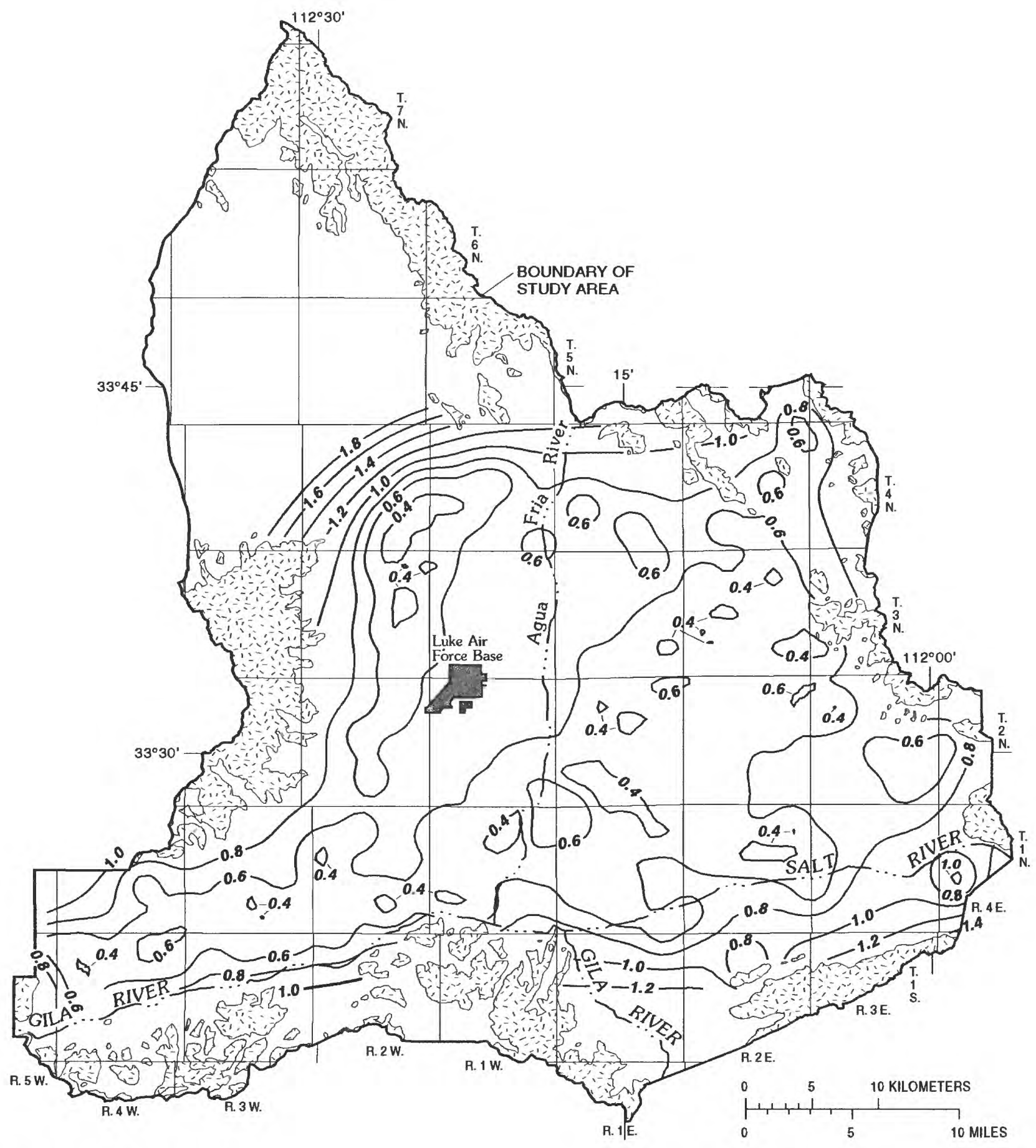

Base from U.S. Geological Survey State base map, 1:1,000,000, 1974

EXPLANATION 
For 1980-85 (fig. 16), cokriged variances were less than 0.8 for almost all of the study area south of $33^{\circ} 45^{\prime}$ latitude and east of $112^{\circ} 30^{\prime}$ longitude. Variances were between 0.6 and 0.8 throughout Buckeye Valley and between the White Tank Mountains and the Agua Fria River. In the Phoenix area, cokriged variances generally were between 0.4 and 0.6. Variances for this data set generally were lower than those for the 1975-77 and 1986-90 data sets and reflected the more even distribution of data for 1980-85. For the 1986-90 data set (fig. 17), cokriged variances were less than 0.8 for much of the study area south of $33^{\circ} 45^{\prime}$ latitude and east of $112^{\circ} 30^{\prime}$ longitude, but generally were between 0.8 and 1.4 along the margins of the valley. Some locations in Buckeye Valley had variances for 1986-90 that were lower than for 1980-85; in other locations, the reverse was true. Although the variance is an important part of the cokriging process, it is only the true estimation variance if the model chosen corresponds to the actual process or processes that control the distribution of the variables of interest. In general, the variance is used more properly as a barometer of the sampling pattern as it pertains to the estimation process at different sites.

\section{Nitrate Variation With Land Use}

Land-use maps were used in conjunction with the cokriged nitrate distributions in order to examine the spatial and temporal relation between land use and nitrate concentration. Two digitized land-use maps of west Salt River Valley were used in this study. A land-use map for 1973 was used with the water-chemistry data for 1975-77, and a map for 1987 was used with the water-chemistry data for 1980-85 and 1986-90. The 1973 map was obtained in digital form from the USGS Earth Sciences Information Center. The 1987 map was constructed for this study from aerial photographs (McLain Harbors Co., Inc., 1987). Because the map for 1987 was based on aerial photography and was not field checked, this map was more generalized than the map for 1973. For example, the map for 1973 distinguished between commercial and industrial land-use types. Such a distinction generally was not possible using aerial photography. Land-use types on the 1973 map were combined in such a way as to make the classification categories the same for both maps. Land use was classified into the five categories for statistical analysis:

1. Residential, industrial, and commercial;

2. Crops and pastures;

3. Orchards and groves;

4. Cattle (feedlots and dairies); and

5. Range land (natural desert vegetation).

Over the past several decades, agricultural land has been replaced steadily by residential and commercial property. From 1973 to 1987 , the area devoted to crops and pastures decreased from 42 to 38 percent, and the range land decreased from 37 to 34 percent (tables 6 and 7). Residential, industrial, and commercial land increased from 19 to 31 percent. The area occupied by orchards and groves doubled from 1 to 2 percent of the total basin area.

Because data points for $1980-85$ are well distributed throughout the study area, this data set provides a representative picture of the relation (or lack of) between land use and nitrate concentrations in ground water. From data for 1980-85, average nitrate concentration was $8.25 \mathrm{mg} / \mathrm{L}$ in ground water underlying residential, industrial, and commercial areas and $9.82 \mathrm{mg} / \mathrm{L}$ in ground water underlying crop and pasture land (table 6). Although the average values differ by only about $2 \mathrm{mg} / \mathrm{L}$ and both nitrate concentration averages are below $10 \mathrm{mg} / \mathrm{L}, 27$ percent of kriged nitrate values in ground water underlying residential, industrial, and commercial areas exceeded $10 \mathrm{mg} / \mathrm{L}$, and 47 percent of kriged nitrate values in ground water underlying crop and pasture land exceeded $10 \mathrm{mg} / \mathrm{L}$ (table 6). Even though almost half of the kriged nitrate values in ground water underlying agricultural areas exceeded the MCL for nitrate, nitrate concentrations in ground water below extensive agricultural areas remained below $10 \mathrm{mg} / \mathrm{L}$. For example, although Tps. 3 and $4 \mathrm{~N}$., Rs. 1 and 2 W., have been irrigated for decades, nitrate concentrations in ground water underlying this area are less than $5 \mathrm{mg} / \mathrm{L}$. Depths to ground water in much of this area exceeded $120 \mathrm{~m}$ in 1983 (Reeter and Remick, 1986), which indicates that in areas with large unsaturated zones, large-scale irrigation does not necessarily result in nitrate contamination in ground water. Conversely, in Buckeye Valley and other areas where the water 
Table 6. Average nitrate concentrations from cokriged maps for different land-use types

\begin{tabular}{|c|c|c|c|c|c|c|}
\hline \multirow[b]{2}{*}{ Land-use type } & \multicolumn{3}{|c|}{$\begin{array}{l}\text { Average nitrate concentrations, in } \\
\text { milligrams per liter as nitrogen }\end{array}$} & \multicolumn{3}{|c|}{$\begin{array}{l}\text { Percentage of nitrate concentrations } \\
\text { exceeding } 10 \text { milligrams per liter as } \\
\text { nitrogen }\end{array}$} \\
\hline & $1975-77$ & $1980-85$ & $1986-90$ & $1975-77$ & $1980-85$ & $1986-90$ \\
\hline Residential, industrial, commercial .... & 10.25 & 8.25 & 9.94 & 43 & 27 & 41 \\
\hline Crop and pasture & 9.80 & 9.82 & 9.29 & 35 & 47 & 39 \\
\hline Orchards and groves & 7.51 & 4.42 & 5.68 & 9 & 1 & 5 \\
\hline Cattle & 6.48 & 10.16 & 7.91 & 16 & 43 & 31 \\
\hline 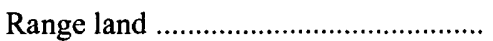 & 5.76 & 2.64 & 1.91 & 22 & 5 & 3 \\
\hline
\end{tabular}

Table 7. Percentage of area on land-use map represented by indicated land use, and percentage of land underlain by ground water that contains nitrate concentrations greater than 10 milligrams per liter as $\mathrm{N}$

[mg/L, milligrams per liter]

\begin{tabular}{|c|c|c|c|c|}
\hline \multirow[b]{2}{*}{ Land-use type } & \multicolumn{2}{|c|}{ Land-use map, 1973} & \multicolumn{2}{|c|}{ Land-use map, 1987} \\
\hline & $\begin{array}{c}\text { Area of } \\
\text { indicated } \\
\text { land use, in } \\
\text { percent }\end{array}$ & $\begin{array}{l}\text { Area of indicated land } \\
\text { use with ground water } \\
\text { containing more than } \\
10 \text { milligrams per liter } \\
\text { nitrate as nitrogen, } \\
\text { in percent }\end{array}$ & $\begin{array}{l}\text { Area of indicated } \\
\text { land use, in } \\
\text { percent }\end{array}$ & $\begin{array}{l}\text { Area of indicated land } \\
\text { use with ground water } \\
\text { containing more than } \\
10 \text { milligrams per liter } \\
\text { nitrate as nitrogen, } \\
\text { in percent }\end{array}$ \\
\hline $\begin{array}{l}\text { Residential, industrial, com- } \\
\text { mercial }\end{array}$ & 19 & 34 & 31 & 50 \\
\hline Crop and pasture & 42 & 63 & 34 & 47 \\
\hline Orchards and groves ................ & 1 & .3 & 2 & 0 \\
\hline Cattle & .5 & .3 & .3 & 1 \\
\hline$\ldots$ & 37 & 2 & 33 & 2 \\
\hline
\end{tabular}

table is shallow, nitrate concentrations in ground water underlying agricultural lands generally exceed $10 \mathrm{mg} / \mathrm{L}$.

Range land (natural desert vegetation) was associated with the smallest nitrate concentrations of all land-use categories for 1980-85. Just 2 percent of range land was underlain by ground water containing nitrate concentrations in excess of $10 \mathrm{mg} / \mathrm{L}$, and the average nitrate concentration in ground water underlying range land was $2.64 \mathrm{mg} / \mathrm{L}$. Only 1 percent of the kriged nitrate values in ground water underlying orchards and groves exceeded $10 \mathrm{mg} / \mathrm{L}$ (table 6) because most orchards were in areas where ground-water levels are more than $60 \mathrm{~m}$ below the land surface.

Although some temporal trends are evident, the measured changes in cokriged nitrate distribution through time are not clear because distribution of data differs significantly from one data set to another. For example, in Buckeye Valley, the data for 1975-77 are limited mainly to analyses from wells distributed linearly along two major irrigation canals. Cokriged lines of equal nitrate concentration generally are aligned perpendicular to the canals, and the cokriged variances increase with increasing distance from the data locations. On the other hand, data for 1980-85 are more evenly distributed. The cokriged nitrate distribution for 1980-85 better represents the decrease in nitrate concentrations from the axis of the valley to the flanks of the White Tank Mountains and the Buckeye Hills; however, the cokriged nitrate distribution for 1975-77 does not. For that reason, changes through time in the average nitrate values (table 6) and the percentage of land use underlain by ground water containing more than $10 \mathrm{mg} / \mathrm{L}$ nitrate as $\mathrm{N}$ (table 7) may reflect different data distributions rather than actual 
changes in nitrate concentrations in ground water. A better approach in this situation would be to examine changes over time at selected wells that are sampled on at least an annual basis.

The covariance associated with each cokriged estimation may be an additional source of uncertainty. Data in tables 6 and 7 do not take the uncertainty in the cokriging values into account. Such uncertainty could lead to a bias in the averages. Although data in tables 6 and 7 represent the best available information, the data should be used with full knowledge of the inherent limitations.

\section{CONSIDERATIONS FOR FURTHER STUDY}

Although a variety of statistical analyses were used in this study, additional analyses and variation on those analyses might be useful. One promising avenue of investigation would be to incorporate the time of sampling into the cokriging process as a third coordinate. The fact that sites were combined at a wide range of times into a single data set means that a factor was introduced that may have obscured the results. Including the time of sampling into this analysis was outside the scope of this investigation. Time could be incorporated into this analysis in the same way spatial coordinates were utilized.

Maps created for comparison purposes might have been better represented as ratios with respect to the best map and may have served as a better visual representation of the results. One reviewer emphasized the value of cokriging in the undersampled case. Because there was no undersampled case in this study, little time and effort on that aspect of cokriging was expended; however, this potential is important for future studies that use cokriging. In the event that the variable of interest is correlated with another variable that is more accessible, cokriging becomes even more attractive, and kriging, radial-basis function, and inverse-distance squared-weighting schemes are not as attractive.

\section{SUMMARY AND CONCLUSIONS}

Statistical analyses were used to produce maps representing the nitrate distribution in ground water from west Salt River Valley. These maps were developed to provide a better management tool for ground water affected by large nitrate concentrations. Ground water in large areas of the study area exceed the maximum contaminant level for nitrate set by the USEPA of $10 \mathrm{mg} / \mathrm{L}$ as $\mathrm{N}$. Multiple sources of nitrogen exist in this area and include human activities and natural sources. Because this area is a major population center, reliable maps of water quality and other environmental characteristics are important for optimal management of ground water. Three sets of ground-water data for three time periods1975-77, 1980-85, and 1986-90-were used to analyze temporal as well as spatial variations in nitrate.

The method used to produce the maps is an important factor. This study determined the most accurate, reliable, and easy-to-use method of estimating nitrate concentrations to achieve the desired results. Many software packages are capable of providing estimates, three-dimensional plots, and contour maps; however, the algorithm used may not be well documented, and the user may not be aware of the assumptions inherent in any algorithm. Knowledge of the algorithm is important because different algorithms may produce noticeably different estimates.

The problem of estimation from data is referred to as ill posed by mathematicians because many solutions are possible although only one true solution may exist. For nitrate concentrations or some other variable, many estimation methods may be used that would yield different results; however, the only way to determine the best method is to collect a sample at that location. Verification usually is impractical or impossible because of the expense of sampling or well drilling. Cokriging is optimal from the standpoint of minimizing estimation variance, but this attribute alone does not always result in better cross-validation results as seen in the results from this study. The additional dimensions may cause matrix handling or modeling problems that may cause the method to break down and give poor results. 
Variogram analysis indicated that nitrate showed little statistical similarity to any other variable including the type of correlation that would be optimal for cokriging with other variables. This poor correlation was suspected to be one reason that cokriging gave results only slightly superior to results from kriging. With the given data sets, the increased difficulties of the cokriging process probably do not justify its use compared to the simpler and more straightforward approach of kriging.

Variogram and cross-variogram analysis indicated that nitrate had a short range in comparison with other variables. Even so, several other variables ultimately were selected for intensive treatment and included bicarbonate, magnesium, calcium, sodium, chloride, sulfate, and depth to water. Other variables were excluded from analysis because they did not show particularly strong correlation and were not broadly represented in the data for all time periods.

Cross-validation statistics indicate that for the data sets used in this study, cokriging estimates were slightly more reliable than estimates made by kriging. Cross-validation results, however, indicate that nitrate cokriged best with magnesium for 1975-77 and 1986-90 and with calcium for 1980-85. As expected, cokriging and kriging produced better maps than did the radial-basis function and the inverse-distance squaredweighting methods. When the difficulties and potential problems related to cokriging are weighted against the reliability of the resulting contours or estimates, however, kriging might be preferred for producing reliable maps of nitrate distribution. If future data sets indicate sufficient correlation among the variables of interest or should the undersampled case be a possibility, the increased reliability of a cokriged estimate may justify the additional hazards especially if the user has the ability to do the necessary modeling and cross validation in order to fully assess the cokriging results. Because of problems related to ill-conditioned matrices, reliable global cokriging using these data sets was possible only when limited to nitrate and one or two other variables. Attempts to cokrig with five or six variables were unsuccessful because of matrix and modeling problems.
In Buckeye Valley, cokriging contours of equal nitrate concentration for 1975-77 trend roughly north to south and extend to the north and south margins. This trend reflects, in part, the linear northeast-southwest trend of available nitrate data. In contrast to the nitrate data for 1975-77, the nitrate data for 1980-85 are more evenly and widely distributed. As a result, the cokriged contours for 1980-85 better reflect the general distribution of nitrate than do contours for 1975-77.

Cokriged nitrate concentrations for data from 1980-85 exceeded $20 \mathrm{mg} / \mathrm{L}$ in a 12-squarekilometer area in Phoenix and Glendale and exceeded $10 \mathrm{mg} / \mathrm{L}$ in a 280 -square-kilometer area that extended to the Salt River in the southwest quarter of T. 1 N., R. 2 E. Data for 1986-90 resulted in nitrate concentrations along the entire reach of the Salt River in west Salt River Valley that were less than $10 \mathrm{mg} / \mathrm{L}$ and probably were the result of recharge of runoff from the Salt and Gila Rivers in 1978, 1980, and 1983 during higher-thannormal precipitation. Although the latter two periods of recharge occurred during 1980-85, they did not have an immediate effect on nitrate concentrations throughout much of the arca along the Salt and Gila Rivers. Farther north in Phoenix and Glendale, the area in which nitrate concentrations exceeded $10 \mathrm{mg} / \mathrm{L}$ expanded to $490 \mathrm{~km}^{2}$ for $1986-90$. In Buckeye Valley, nitrate concentrations exceeded $10 \mathrm{mg} / \mathrm{L}$ in a 300 -squarekilometer area for $1980-85$ and in a 220 -squarekilometer area for 1986-90. The measured decrease is likely the result of recharge from the Gila River in the early 1980's, but possibly could be an artifact of the different data distributions associated with each data set. In the Phoenix area, cokriged nitrate concentrations for 1975-77 exceeded $10 \mathrm{mg} / \mathrm{L}$ in a 290 -square-kilometer area and exceeded $20 \mathrm{mg} / \mathrm{L}$ in a 1.4-square-kilometer area.

A relation between nitrate in ground water and land use was completed by comparing the cokriging results with land-use maps. Correlation of nitrate with land use was obscured by the variations in the distribution of data between data sets. One apparent relation was the overrepresentation of urban lands and crop and pasture lands in the areas of increased nitrate 
concentrations. For 1973, 19 percent of the land was classified as urban, and 42 percent as crop and pasture land; however, these two land-use types accounted for 34 percent and 63 percent of the nitrate concentrations, respectively, in excess of the limit of $10 \mathrm{mg} / \mathrm{L}$. A similar picture prevailed on the map for 1987 in which 31 percent of the land use was urban and 34 percent was crop and pasture land. These two land-use types accounted for 50 percent and 47 percent, respectively, of the excessive nitrate values.

\section{REFERENCES CITED}

Anderson, T.W., 1968, Electrical-analog analysis of ground-water depletion in central Arizona: U.S. Geological Survey Water-Supply Paper 1860, $21 \mathrm{p}$.

Anderson, T.W., Freethey, G.W., and Tucci, P., 1992, Geohydrology and water resources of alluvial basins in south-central Arizona and parts of adjacent States: U.S. Geological Survey Professional Paper 1406-B, 67 p.

Brown, J.G., and Pool, D.R., 1989, Hydrogeology of the western part of the Salt River Valley area, Maricopa County, Arizona: U.S. Geological Survey Water-Resources Investigations Report 88-4202, 5 sheets.

Chbouki, Nabil, 1992, Spatio-temporal characteristics of drought as inferred from tree-ring data in Morocco: Tucson, University of Arizona doctoral dissertation, $243 \mathrm{p}$.

Cressie, N., 1985, Fitting variogram models by weighted least squares: Mathematical Geology, v. 17 , no. 5 , p. $563-586$.

Davis, J.C., 1985, Statistics and data analysis in geology: New York, John Wiley and Sons, 464 p.

Englund, E. and Sparks, A., 1991, Geo-EAS 1.2.1 User's Guide: U.S. Environmental Protection Agency Report 600/8-91/008, v.p.

Gellenbeck, D.J., 1994, Isotopic compositions and sources of nitrate in ground water from western Salt River Valley, Arizona: U.S. Geological Survey Water-Resources Investigations Report $944063,53 \mathrm{p}$.

Goovaerts, Pierre, 1992, Multivariate geostatistical tools for studying scale-dependent correlation structures and describing space-time variations: Louvainla-Neuve, Belgium, Universite Catholique de Louvain, doctoral dissertation.
1994, On a controversial method for modeling a coregionalization: Mathematical Geology, v. 20, no. 2, p. 197-204.

Hammett, B.A., and Herther, R.L., 1995, Maps showing groundwater conditions in the Phoenix Active Management Area, Maricopa, Pinal, and Yavapai Counties, Arizona-1992: Phoenix, Arizona Department of Water Resources Hydrologic Map Series Report Number 27, 3 sheets.

Helsel, D.R., 1990, Less than obvious-Statistical treatment of data below the detection limit: Environmental Science and Technology, v. 24, no. 12 , p. 1766-1774.

Kam, William, Schumann, H.H., Kister, L.R., Arteaga, F.E., 1966, Basic ground-water data for western Salt River Valley, Maricopa County, Arizona: Arizona State Land Department Water-Resources Report 27, 72 p.

Kister, L.R., 1974, Dissolved-solids content of ground water in the Phoenix area, Arizona: U.S. Geological Survey Miscellaneous Investigations Map I-845-G, 1 sheet.

Konieczki, A.D., and Wilson, R.P., 1992, Annual summary of ground-water conditions in Arizona, spring 1986 to spring 1987: U.S. Geological Survey Open-File Report 92-54, 1 sheet.

Lee, W.T., 1905, Underground waters of Salt River Valley, Arizona: U.S. Geological Survey Water-Supply Paper 136, $196 \mathrm{p}$.

Long, A.E., 1994, Cokriging, kernels, and the SVD-Toward better geostatistical analysis: Tucson, University of Arizona doctoral dissertation, $253 \mathrm{p}$.

Mann, L.J., and Rohne, P.B., Jr., 1983, Streamflow losses and changes in ground-water levels along the Salt and Gila Rivers near Phoenix, Arizona-February 1978 to June 1980: U.S. Geological Survey Water-Resources Investigations Report 83-4043, 11 p.

Maricopa Association of Governments, 1978, Groundwater quality in the major basins of Maricopa County: Phoenix, Arizona, Maricopa Association of Governments 208 program, v.p. 1979, Nonpoint sources of groundwater pollution: Phoenix, Arizona, Maricopa Association of Governments 208 program, v.p.

1981, Results of the initial groundwater quality monitoring phase (November 1979-January 1981): Phoenix, Arizona, Maricopa Association of Governments 208 program, v.p.

1983, Results of the final groundwater quality monitoring phase (November 1981-September 1983): Phoenix, Arizona, Maricopa Association of Governments 208 program, v.p. 
McLain Harbors Co., Inc., 1987, Aerial photo guide-Valley of the Sun: Tucson, Arizona, McLain Harbors Co., Inc., Aerial Mapping and Surveying, $276 \mathrm{p}$.

Reeter, R.W., and Remick, W.H., 1986, Maps showing groundwater conditions in the West Salt River, East Salt River, Lake Pleasant, Carefree, and Fountain Hills sub-basins of the Phoenix Active Management Area, Maricopa, Pinal, and Yavapai Counties, Arizona-1983: Phoenix, Arizona Department of Water-Resources Hydrologic Map Series Report 12, 3 sheets.

Robertson, F.N., 1991, Geochemistry of ground water in alluvial basins of Arizona and adjacent parts of Nevada, New Mexico, and California: U.S. Geological Survey Professional Paper 1406-C, $90 \mathrm{p}$.
Salt River Project, 1982, Water quality in the Salt River Project-A preliminary report: Phoenix, Arizona Salt River Project report, v.p.

Sellers, W.D., Hill, R.H., and Sanderson-Rae, Margaret, eds., 1985, Arizona climate-The first hundred years: Tucson, Arizona, University of Arizona Press, $80 \mathrm{p}$.

Smith, S.A., 1986, Changes in ground-water quality in the Salt River Project-1982 to 1985: Phoenix, Arizona, Salt River Project report, v.p.

U.S. Environmental Protection Agency, 1991, National revised drinking-water regulations-Maximum contaminant level: Code of Federal Regulations, Title 40, Subpart G, section 141.62, July 1, 1991, p. 673. 